EUROPEAN CENTRAL BANK

WORKING PAPER SERIES

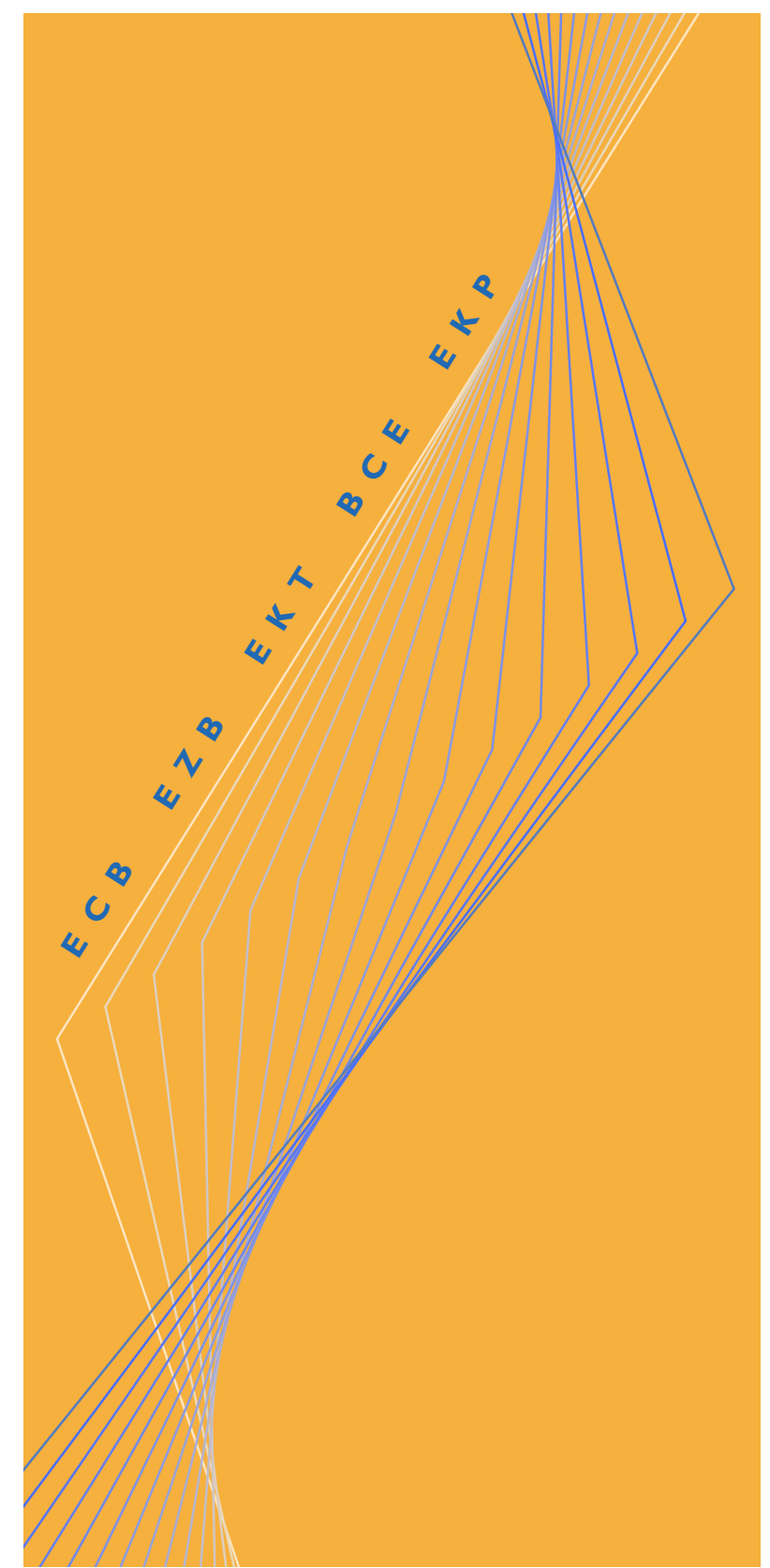

WORKING PAPER NO. 68

THE PERFORMANCE OF

FORECAST-BASED

MONETARY POLICY

RULES UNDER MODEL

UNCERTAINTY

BY ANDREW LEVIN,

VOLKER WIELAND AND

JOHN C.WILLIAMS

July 200 I 


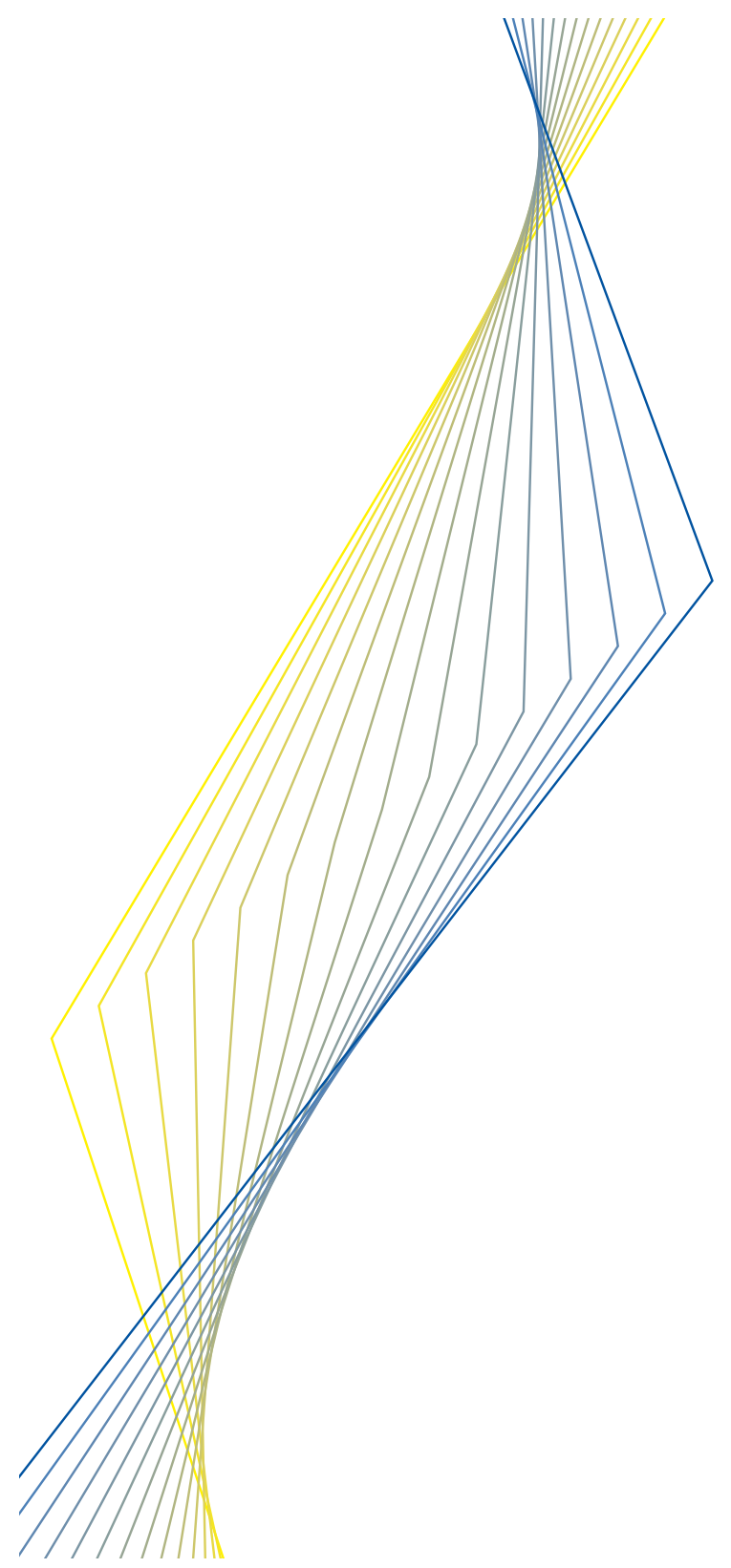

WORKING PAPER NO. 68

\section{THE PERFORMANCE OF FORECAST-BASED MONETARY POLICY RULES UNDER MODEL UNCERTAINTY*}

\section{BY ANDREW LEVIN, VOLKER WIELAND AND JOHN C.WILLIAMS}

\section{July 200 I}


() European Central Bank, 200I

\section{Address}

Postal address

Telephone

Internet

Fax

Telex
Kaiserstrasse 29

D-603 I I Frankfurt am Main

\section{Germany}

Postfach 160319

D-60066 Frankfurt am Main

\section{Germany}

+4969 I3440

http://www.ecb.int

+4969 I3446000

4 | | | 44 ecb d

All rights reserved.

Reproduction for educational and non-commercial purposes is permitted provided that the source is acknowledged.

The views expressed in this paper are those of the authors and do not necessarily reflect those of the European Central Bank. 


\section{Contents}

$\begin{array}{ll}\text { Abstract } & 4\end{array}$

I Introduction

2 Specification of Forecast-based Policy Rules 7

2.I The Case for Preemptive Policy $\quad 7$

$\begin{array}{lll}2.2 & \text { Forecast-Based Rules from the Literature } & 10\end{array}$

3 Indeterminacy of Rational Expectations Equilibria $\quad 12$

3.I Multiple Equilibria in an Optimizing AD-AS Model $\quad 12$

3.2 Multiple Equilibria in the Four Macroeconometric Models 16

$\begin{array}{ll}\text { 3.3 Behavior of Forecast-Based Rules from the Literature } & 19\end{array}$

4 Optimized Forecast-Based Rules 21

$\begin{array}{lr}\text { 4.I The Optimization Problem } & 21\end{array}$

5 Robustness of Optimized Rules unde Model Uncertainty 26

5.I Robustness with Model-Consistent Forecasts 27

$\begin{array}{ll}5.2 \text { Robustness with Model-Inconsistent Forecasts } & 29\end{array}$

$\begin{array}{ll}5.3 \text { Rules with Fixed Forecast Horizons } & 30\end{array}$

6 Identifying a Robust Benchmark Rule 3 I

7 Conclusions $\quad 34$

$\begin{array}{ll}\text { A Appendix } & 35\end{array}$

$\begin{array}{ll}\text { A.I Forecast-Based Policy Rules Fron the Literature } & 35\end{array}$

A.2 The Five Macroeconomic Models $\quad 36$

$\begin{array}{lr}\text { A.3 Methodology } & 39\end{array}$

A.4 Coefficients of Optimized Rules $\quad 42$

A.5 Additional Robustness Results $\quad 43$

$\begin{array}{lr}\text { References } & 47\end{array}$

European Central Bank Working Paper Series 


\begin{abstract}
We investigate the performance of forecast-based monetary policy rules using five macroeconomic models that reflect a wide range of views on aggregate dynamics. We identify the key characteristics of rules that are robust to model uncertainty: such rules respond to the one-year ahead inflation forecast and to the current output gap, and incorporate a substantial degree of policy inertia. In contrast, rules with longer forecast horizons are less robust and are prone to generating indeterminacy. In light of these results, we identify a robust benchmark rule that performs very well in all five models over a wide range of policy preferences.
\end{abstract}

KEYWORDS: Inflation forecast targeting, optimal monetary policy.

JEL Classification System: E31, E52, E58, E61 


\section{Introduction}

A number of industrialized countries have adopted explicit inflation forecast targeting regimes, in which the stance of policy is adjusted to ensure that the inflation rate is projected to return to target over a specified horizon. ${ }^{1}$ Such a regime has also received formal consideration recently by the Bank of Japan, while Svensson (1999) and others have recommended that the Federal Reserve and the European Central Bank should follow suit. ${ }^{2}$ In principle, forecast-based policies can incorporate comprehensive and up-to-date macroeconomic information and can account for transmission lags and other structural features of the economy. Furthermore, the relative simplicity of such rules may serve in facilitating public communication regarding monetary policy objectives and procedures. ${ }^{3}$

The existing literature on forecast-based policy rules has generally proceeded by computing rules that are optimal or near-optimal for a specific macroeconometric model. ${ }^{4}$ However, given substantial uncertainty about the "true" structure of the economy (cf. McCallum (1988), Taylor (1999b)), it is essential to identify the characteristics of policy rules that perform well across a reasonably wide range of models; that is, to identify rules that are robust to model uncertainty. ${ }^{5}$ This approach seems particularly important in analyzing forecast-based rules, since the performance of these rules is contingent on the accuracy of the forecasting model. Furthermore, with an inappropriate choice of policy parameters, forecast-based rules may fail to ensure a unique stationary rational expectations equilibrium (cf. Bernanke and Woodford (1997), Woodford (2000a)); in such cases, excessive macroeconomic volatility can result from self-fulfilling expectations that are unrelated to macroeconomic fundamentals.

Thus, in this paper we investigate the performance and robustness of forecast-based rules using four structural macroeconometric models that have been estimated using postwar U.S. data, along

\footnotetext{
${ }^{1}$ Leiderman and Svensson, eds (1995), Bernanke and Mishkin (1997), and Bernanke, Laubach, Mishkin and Posen (1999) provide extensive background on and analysis of inflation targeting regimes in Australia, Canada, Israel, New Zealand, Sweden, and the United Kingdom. Explicit inflation targeting has also been adopted by a substantial number of emerging market countries; see Schaecter, Stone and Zelmer (2000).

${ }^{2}$ Svensson (1999), Goodhart (2000), and Svensson and Woodford (1999) recommend that central banks commit to an inflation forecast-targeting rule.

${ }^{3}$ Clarida and Gertler (1997), Clarida, Gali and Gertler (1998), Orphanides (1998b), and Chinn and Dooley (1997) have found that estimated forecast-based reaction functions provide reasonably accurate descriptions of interest rate behavior in Germany, Japan, and the United States during the 1980s and 1990s. Therefore, adopting an explicit forecast-based rule as a policy benchmark might primarily involve a change in the communication of policy, and not necessarily a major shift in policy actions.

${ }^{4}$ Such research has been performed at the Reserve Bank of Australia (de Brouwer and Ellis (1998)), the Bank of Canada (Black, Macklem and Rose (1997a); Amano, Coletti and Macklem (1999)), the Bank of England (Haldane, ed (1995), Batini and Haldane (1999); Batini and Nelson (2001)), and the Reserve Bank of New Zealand (Black, Cassino, Drew, Hansen, Hunt, Rose and Scott (1997b)). Rudebusch and Svensson (1999) analyzed the performance of instrument and targeting rules in a small adaptive-expectations model of the U.S. economy.

${ }^{5}$ Monetary policy under model uncertainty has previously been analyzed by Karakitsos and Rustem (1984), Becker, Dwolatsky, Karakitsos and Rustem (1986), Frankel and Rockett (1988), Holtham and Hughes-Hallett (1992), and Christodoulakis, Kemball-Cook and Levine (1993). Most recently, Levin, Wieland and Williams (1999) evaluated the robustness to model uncertainty of optimized simple policy rules involving current and lagged macroeconomic variables, while Taylor (1999a) summarizes the performance of five rules in an even wider range of macroeconomic models.
} 
with a small stylized model derived from microeconomic foundations with calibrated parameter values. All five models incorporate the assumptions of rational expectations, short-run nominal inertia, and long-run monetary neutrality. Nevertheless, these models exhibit substantial differences in price and output dynamics, reflecting ongoing theoretical and empirical controversies as well as differences in degree of aggregation, estimation method and sample period, etc.

We assume that the policymaker is able to commit to a time-invariant rule, and that the policymaker's objective is to minimize a weighted sum of the unconditional variances of the inflation rate and the output gap, subject to an upper bound on nominal interest rate volatility. ${ }^{6}$ We focus on simple forecast-based rules in which the short-term nominal interest rate is adjusted in response to current or projected future values of the inflation rate and the output gap as well as to the lagged nominal interest rate. We begin by determining the conditions on the policy rule parameters (including the choice of forecast horizon) that are required to ensure a unique stationary rational expectations equilibrium in each model. Next we determine the optimal forecast horizons and other policy parameters that minimize the policymaker's loss function in each model, and we analyze the robustness of each optimized rule by evaluating its performance in each of the other models. Having identified a particular class of robust policy rules, we proceed to determine the policy parameters that minimize the average loss function across all five models; from a Bayesian perspective, this approach corresponds to the case in which the policymaker has flat prior beliefs about the extent to which each model provides an accurate description of the true economy.

Our analysis concludes by identifying a specific forecast-based policy rule that can serve as a robust benchmark for monetary policy; this rule performs remarkably well for a wide range of policy preferences as well as for a wide range of prior beliefs about the dynamic properties of the economy. More generally, our results provide strong support for policy rules that respond to a short-horizon forecast (no more than one year ahead) of a smoothed measure of inflation, that incorporate a substantial response to the current output gap, and that involve a relatively high degree of policy inertia (also referred to as "interest rate smoothing"). ${ }^{7}$ We find that such rules are highly robust to model uncertainty, whereas rules that utilize longer-horizon inflation forecasts and rules that omit an explicit output gap response are much less robust, and in fact are particularly prone to generating multiple equilibria.

Finally, it should be noted that our approach of evaluating the robustness of monetary policy rules to model uncertainty is complementary to Bayesian methods that analyze the policy implications of uncertainty about the parameters of a particular model, as well as to robust control methods that indicate how to minimize the "worst-case" losses due to perturbations from a given

\footnotetext{
${ }^{6}$ For recent analysis of the monetary policy implications of time-inconsistency and commitment vs. discretion, see Söderlind (1999), Woodford (1999), Svensson and Woodford (2000), and Svensson (2001).

${ }^{7}$ For analysis of interest rate smoothing in outcome-based rules, see Goodfriend (1991), Rotemberg and Woodford (1999), Williams (1999), Levin et al. (1999), Sack and Wieland (2000), Woodford (1999), and Woodford (2000b).
} 
model. ${ }^{8}$ Unlike these other approaches, however, our method naturally lends itself to situations in which non-nested models represent competing perspectives regarding the dynamic structure of the economy.

The remainder of this paper proceeds as follows. Section 2 highlights the key issues regarding the specification of forecast-based policy rules. In Section 3, we analyze the restrictions on such rules that are required to ensure a unique rational expectations equilibrium. In Section 4, we analyze the properties of forecast-based rules that are optimized for each individual model. Section 5 considers the extent to which these optimized rules are robust to model uncertainty, and identifies the characteristics of robust policy rules. In Section 6 , we find the policy parameters that minimize the average loss function across all five models, and then we identify a specific forecast-based rule that can serve as a benchmark for policy analysis. Section 7 summarizes our conclusions and considers directions for further research. Finally, the Appendix provides background information regarding alternative forecast-based policy rules taken from the literature, as well as further details about the models and about the solution and optimization methods used in this paper.

\section{Specification of Forecast-based Policy Rules}

In this section, we consider the choices involved in specifying a forecast-based monetary policy rule, in light of the theoretical arguments for these rules as well as the characteristics of various rules that have been considered in the literature. As noted above, we focus our attention on rules in which the short-term nominal interest rate responds directly to a small set of variables such as the inflation rate, the output gap, and the lagged interest rate.

\subsection{The Case for Preemptive Policy}

One intuitively appealing argument for forecast-based rules is that monetary policy acts with a substantial lag, and hence current policy actions should be determined in light of the macroeconomic conditions that are expected to prevail when such actions will have substantial effect. (This rationale is referred to as "lag encompassing" by Batini and Haldane (1999).) Of course, since every forecast can be expressed in terms of current and lagged state variables, a forecast-based rule cannnot yield any improvement in macroeconomic stability relative to the fully optimal policy rule (which incorporates all of the relevant state variables). However, a simple forecast-based policy rule might perform substantially better than a simple outcome-based rule (that is, a rule involving only a small set of current and lagged variables). For example, consider a sharp hike in import oil prices that gradually passes through to prices of domestically-produced output: an outcome-based policy

\footnotetext{
${ }^{8}$ Optimal policy under parameter uncertainty was investigated in the seminal paper of Brainard (1967) and was extended by the work of Kendrick (1982) and others; recent examples include Balvers and Cosimano (1994) and Wieland (2000). Applications of robust control methods include von zur Muehlen (1982), Hansen and Sargent (1997), Stock and Onatski (1999), Giannoni (2000), and Tetlow and von zur Muehlen (2000).
} 
rule reacts only as the inflationary effects are realized, whereas a forecast-based rule can respond immediately to the shock and hence get a head start in restraining its inflationary effects.

In this paper, we analyze the performance of monetary policy rules using five models of the U.S. economy. The small stylized model (described further in Section 3) has no intrinsic inertia, while each of the four macroeconometric models incorporates nontrivial monetary transmission lags. In particular, the Fuhrer-Moore (FM) model exhibits the highest degree of inertia with respect to both aggregate demand and inflation (cf. Fuhrer and Moore (1995)). In the Federal Reserve Board (FRB) model, prices and spending are subject to higher-order adjustment costs; this model also features a relatively detailed representation of the supply side of the economy (cf. Brayton, Mauskopf, Reifschneider, Tinsley and Williams (1997b), Reifschneider, Tetlow and Williams (1999)). In Taylor's (1993) multicountry model - hereafter referred to as TMCM prices are determined by staggered wage contracts, while consumption and investment expenditures are explicitly forward-looking and exhibit relatively little intrinsic inertia. Finally, the Monetary Studies Research (MSR) model developed by Orphanides and Wieland (1998) exhibits output dynamics similar to that of TMCM and inflation dynamics similar to that of the FM model.

To compare the properties of these models, we utilize an estimated federal funds rate equation as a benchmark policy rule (henceforth referred to as rule A). In particular, using U.S. quarterly data for the period 1980:1-1998:4, we estimated the following equation via two-stage least squares:

$$
i_{t}=-\underset{(.31)}{.28}+\underset{(.06)}{.76} i_{t-1}+\underset{(.11)}{.60} \tilde{\pi}_{t}+\underset{(.25)}{.21} y_{t}-\underset{(.23)}{.97} \Delta y_{t}
$$

where $i$ denotes the short-term nominal interest rate; $y$ denotes the output gap (the deviation of output from potential), and $\tilde{\pi}$ denotes the four-quarter average inflation rate of the chain-weighted GDP price deflator. ${ }^{9}$ All variables are measured at annual rates in percentage points, and the standard error of each regression coefficient is given in parentheses. Using this benchmark policy rule, we solve each model using the methodology described in the Appendix, and then determine its behavior in response to a 100 basis point federal funds rate innovation.

Based on the dynamic behavior of the four macroeconometric models, monetary transmission lags alone can potentially rationalize policy rules that utilize output forecast horizons of up to one year and inflation forecast horizons of up to two years. As shown in Figure 1, the peak response of output occurs with a lag of one to four quarters, while the peak inflation response exhibits a lag of three to nine quarters. For comparison, it is interesting to note that estimated VAR models of the U.S. economy exhibit a monetary transmission lag of about two years for output and a lag

\footnotetext{
${ }^{9}$ The functional form of equation (1) is the same as in Orphanides and Wieland (1998) and Levin et al. (1999), but with a somewhat longer sample period. In estimating this equation, we used the quarterly average federal funds rate, the $\mathrm{CBO}$ output gap series, and the inflation rate of the chain-weighted GDP price deflator. For this regression equation, $\bar{R}^{2}=.93$ and $D W=2.50$.
} 
Figure 1: Impulse Responses to Policy Rule Innovations

Inflation

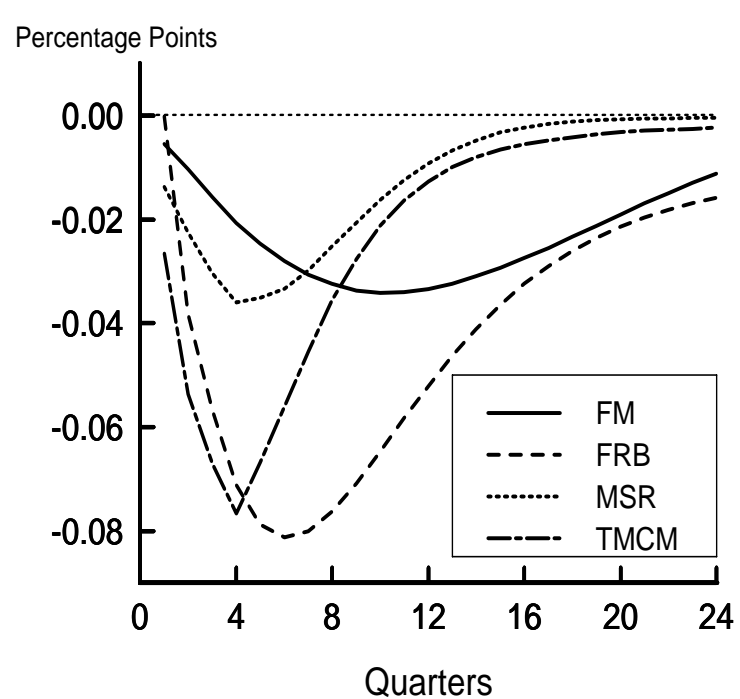

Output Gap

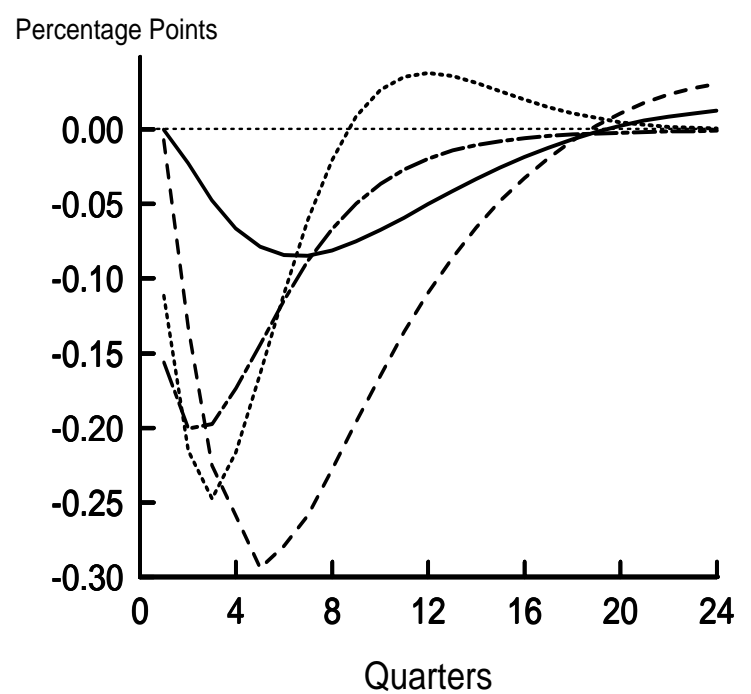

of about three years for inflation (cf. Christiano, Eichenbaum and Evans (1996), Brayton, Levin, Tryon and Williams (1997a)).

A related argument (referred to as "information encompassing" by Batini and Haldane (1999)) is that forecast-based policy rules can implicitly incorporate a wide variety of information regarding the current state of the economy as well as anticipated future developments. For example, a forecast-based rule can automatically adjust the stance of monetary policy depending on whether a given macroeconomic disturbance is expected to persist or to vanish quickly. In contrast, a simple outcome-based rule prescribes a fixed policy response to a given movement in the inflation rate, regardless of whether the underlying shock is transitory or persistent. For this reason, outcomebased rules typically utilize smoothed measures of the inflation rate (e.g., the four-quarter average) in order to dampen the monetary policy response to transitory supply shocks (cf. Williams (1999)). Of course, using a smoothed inflation rate also means that outcome-based rules exhibit a more sluggish response to persistent shocks, and hence might be expected to yield inferior stabilization performance compared with forecast-based rules that utilize non-smoothed measures of inflation.

Finally, it has been argued that monetary policy can effectively stabilize both inflation and output through a rule that only involves inflation forecasts, with no explicit response to the output gap. (Batini and Haldane (1999) refer to this feature of forecast-based rules as "output encompassing.") In principle, the forecast horizon of the rule can be adjusted to reflect the policymaker's preferences for stabilizing output vs. inflation in response to aggregate supply shocks; that is, with a longer inflation forecast horizon, the policy rule brings inflation back to target more gradually and thereby dampens the associated swings in output and employment. To analyze this approach, 
our analysis below includes a detailed evaluation of the performance and robustness of rules that respond only to an inflation forecast and the lagged interest rate.

\subsection{Forecast-Based Rules from the Literature}

In light of the previous discussion, it is evident that several important issues arise in specifying a forecast-based policy rule, including the selection of a particular forecast horizon, the use of a high-frequency or smoothed measure of the inflation rate, and the choice of whether to incorporate an explicit response to the output gap. Thus, it is useful to review the characteristics of policy rules that have been studied in the academic literature as well as rules that are actually used for policy analysis at central banks. For this purpose, we consider the following general specification:

$$
i_{t}=\rho i_{t-1}+(1-\rho)\left(r^{*}+E_{t} \bar{\pi}_{t+\theta}\right)+\alpha\left(E_{t} \bar{\pi}_{t+\theta}-\pi^{*}\right)+\beta E_{t} y_{t+\kappa},
$$

where $r^{*}$ is the unconditional mean of the short-term real interest rate, $\pi^{*}$ is the inflation target, and the inflation measure $\bar{\pi}$ is either the one-quarter inflation rate, $\pi$, or the four-quarter average inflation rate, $\tilde{\pi}$. The operator $E_{t}$ indicates the forecast of a particular variable, using information available in period $t$. The integers $\theta$ and $\kappa$ denote the forecast horizons (measured in quarters) for inflation and the output gap, respectively.

Table 1 reports the specifications of ten forecast-based policy rules taken from the literature; additional information about these rules is provided in the Appendix. Rules B and C were fitted to U.S. data from the past two decades. The parameters of rules D, E, F, J, and K were selected based on favorable stabilization performance in particular macroeconomic models with rational expectations, while the parameters of rules $\mathrm{G}, \mathrm{H}$, and I were chosen based on performance in models with adaptive expectations. Seven of the ten rules exhibit "interest rate smoothing" or "policy inertia"; that is, these rules involve a direct response to the lagged short-term interest rate.

As noted above, the "lag-encompassing" rationale for forecast-based rules suggests a forecast horizon roughly similar to the transmission lag of monetary policy. To highlight this feature, the rules in Table 1 have been grouped into two categories according to the duration of the inflation forecast horizon: two to four quarters for rules B through $\mathrm{F}$; and eight to fifteen quarters for rules $\mathrm{G}$ through K. In all cases, the inflation forecast horizon equals or exceeds the output forecast horizon. The range of forecast horizons in these rules lies within the range of the estimated policy transmission lags for the four macroeconometric models considered here as well as for estimated VAR models of the U.S. economy.

A smoothed measure of inflation (namely, the four-quarter average inflation rate $\tilde{\pi}$ ) is utilized in five of the rules in Table 1 (including rules B and C that were fitted to U.S. data). As discussed above, however, the "information-encompassing" rationale for forecast-based rules suggests that the use of a smoothed measure of inflation might be unnecessary or even counterproductive. Consistent 
Table 1: Characteristics of Forecast-Based Rules from the Literature

\begin{tabular}{|c|c|c|c|c|c|c|c|}
\hline \multicolumn{8}{|c|}{$\begin{array}{c}\text { General Specification } \\
i_{t}=\rho i_{t-1}+(1-\rho)\left(r^{*}+E_{t} \bar{\pi}_{t+\theta}\right)+\alpha\left(E_{t} \bar{\pi}_{t+\theta}-\pi^{*}\right)+\beta E_{t} y_{t+\kappa}\end{array}$} \\
\hline Label & Source & $\bar{\pi}$ & $\theta$ & $\kappa$ & $\rho$ & $\alpha$ & $\beta$ \\
\hline \multicolumn{8}{|c|}{ Inflation Forecast Horizon $\leq 1$ year } \\
\hline $\mathrm{B}$ & Clarida, Gali \& Gertler (1998) & $\tilde{\pi}$ & 4 & 0 & .84 & .27 & .09 \\
\hline $\mathrm{C}$ & Orphanides (1998) & $\tilde{\pi}$ & 4 & 4 & .56 & .27 & .36 \\
\hline $\mathrm{D}$ & de Brouwer \& Ellis (1998) & $\tilde{\pi}$ & 4 & 4 & 0 & 2.80 & 1.00 \\
\hline $\mathrm{E}$ & Batini and Nelson (2001) & $\pi$ & 2 & - & .98 & 1.26 & - \\
\hline $\mathrm{F}$ & Isard, Laxton \& Eliasson (1999) & $\tilde{\pi}$ & $3-4$ & - & 0 & 1.50 & - \\
\hline \multicolumn{8}{|c|}{ Inflation Forecast Horizon $\geq 2$ year } \\
\hline G & Rudebusch \& Svensson (1999) & $\pi$ & 8 & - & .62 & 1.97 & - \\
\hline $\mathrm{H}$ & Rudebusch \& Svensson (1999) & $\pi$ & 12 & - & .71 & 3.57 & - \\
\hline I & Batini \& Nelson (2000) & $\pi$ & 15 & - & .85 & 34.85 & - \\
\hline $\mathrm{J}$ & Amano, Coletti \& Macklem (1999) & \multicolumn{6}{|c|}{$i_{t}=i_{t}^{b}+3.0\left(E_{t} \tilde{\pi}_{t+8}-\pi^{*}\right)$} \\
\hline \multirow[t]{2}{*}{$\mathrm{K}$} & Batini \& Haldane (1999) & \multicolumn{6}{|c|}{$i_{t}=E_{t} \pi_{t+1}+.5 r^{*}+.5\left(i_{t-1}-E_{t-1} \pi_{t}\right)$} \\
\hline & & \multicolumn{6}{|c|}{$+.5\left(E_{t} \pi_{t+8}-\pi^{*}\right)$} \\
\hline
\end{tabular}

Notes: The inflation measure $\bar{\pi}$ is either the one-quarter inflation rate $\pi$ or the four-quarter average inflation rate $\tilde{\pi}$. In rule $\mathrm{F}$, the first inflation forecast (multiplied by the coefficient $1-\rho$ ) uses a 4-quarter horizon, while the second inflation forecast (multiplied by the coefficient $\alpha$ ) uses a 3quarter horizon. The final two rules do not conform to the general specification: rule $\mathrm{J}$ involves the long-term nominal interest rate $i_{t}^{b}$, while rule $\mathrm{K}$ involves the lagged value of the ex ante real interest rate, $i_{t-1}-E_{t-1} \pi_{t}$.

with this view, rules E, G, H, I, and $\mathrm{K}$ involve forecasts of the one-quarter annualized inflation rate.

Seven of the forecast-based policy rules - including all of the rules with inflation forecast horizons longer than one year - do not include an explicit response to a measure of economic activity and hence provide test cases for the "output encompassing" hypothesis described above. In contrast, both estimated rules include positive responses to the output gap. ${ }^{10}$

\footnotetext{
${ }^{10}$ It should be noted that rule A also includes a economically and statistically significant response to the change in the output gap; regression analysis indicates that the same would be true in forecast-based specifications such as those used in rules B and C. The exclusion of this term from those two rules (apparently for reasons of parsimony) implies more passive policy responses than rule $\mathrm{A}$ in terms of output stabilization as well as nominal interest rate variability.
} 


\section{Indeterminacy of Rational Expectations Equilibria}

Since the work of Sargent and Wallace (1975), the issue of indeterminacy has been an important consideration in evaluating the performance of alternative policy rules: if a monetary policy rule yields multiple stationary equilibria in a rational expectations model, then many of these equilibrium paths involve macroeconomic fluctuations that are unrelated to economic fundamentals. ${ }^{11}$ In particular, Bernanke and Woodford (1997) considered a small stylized model and showed that rules utilizing a one-quarter-ahead inflation forecast are prone to generating multiple equilibria. In this section, we extend their analysis to rules with longer forecast horizons, and then we analyze the conditions for determinacy in each of the four macroeconometric models described above. These results enable us to identify several key characteristics of robust policy rules; given these findings, we consider which of the forecast-based rules in Table 1 generate multiple equilibria in these five models.

\subsection{Multiple Equilibria in an Optimizing AD-AS Model}

We start by examining the conditions for determinacy in a small stylized model similar to that used in Bernanke and Woodford (1997) and more recently in Clarida, Gali and Gertler (1999b) and Woodford (2000a). The model consists of the following two equations along with the monetary policy rule given in equation (2):

$$
\begin{gathered}
\pi_{t}=\delta E_{t} \pi_{t+1}+\phi y_{t}+\epsilon_{t}, \\
y_{t}=E_{t} y_{t+1}-\sigma\left(i_{t}-E_{t} \pi_{t+1}-r^{*}{ }_{t}\right),
\end{gathered}
$$

where $\phi>0, \sigma>0$, and $0<\delta<1$. As described in the Appendix, the price-setting equation (3) and the "expectational IS" equation (4) can be derived from the behavior of optimizing agents. The expectational IS equation and the policy rule together can be viewed as determining aggregate demand, while the price-setting equation determines aggregate supply. Thus, in the subsequent discussion we refer to this three-equation model as the "optimizing AD-AS" model.

Outcome-Based Rules. For outcome-based rules in which policy responds to the current annualized one-quarter inflation rate $\pi_{t}$ as well as the current output gap and lagged interest rate, it is straightforward to confirm that determinacy requires that

$$
\alpha>\frac{\delta-1}{\phi} \beta .
$$

For the special case in which policy does not respond to the output gap (that is, $\beta=0$ ), this restriction has a very simple interpretation: a one percentage point rise in the inflation rate eventually

\footnotetext{
${ }^{11}$ For recent analysis of this issue, see Kerr and King (1996), Christiano and Gust (1999), Clarida, Gali and Gertler (1999a), and Woodford (2000a). For a contrary view, see McCallum (1999) and McCallum (2000).
} 
elicits a greater than one percentage point rise in the nominal short-term interest rate. ${ }^{12}$ If policy exhibits a positive response to the current output gap (that is, $\kappa=0$ and $\beta>0$ ), then modestly negative values of $\alpha$ are also consistent with a unique equilibrium in this model.

One-Step-Ahead Inflation Forecast Rules. We now consider the determinacy conditions for forecast-based rules involving $\pi_{t+1}$, the one-step-ahead forecast of the annualized one-quarter inflation rate. In this case, policy is subject to the same lower bound as in equation (5), but now, an additional upper bound on the allowable value of $\alpha$ obtains. In particular, as shown by Woodford (2000a), determinacy requires that the policy parameters satisfy

$$
\frac{\delta-1}{\phi} \beta<\alpha<2 \rho+\frac{1+\delta}{\sigma \phi}(2+2 \rho+\sigma \beta)
$$

With a moderate policy response to expected inflation, there exists a unique stationary equilibrium; that is, any other values of the current output gap and current inflation rate are associated with an explosive path in subsequent periods. In contrast, with a sufficiently aggressive policy response to expected inflation, the output gap and inflation rate are projected to converge back to the steady state regardless of their values in the current period. Thus, at any given point in time, the output gap and inflation rate can suddenly move in response to random shocks that are unrelated to economic fundamentals (often referred to as "sunspots").

The upper bound on $\alpha$ in equation (6) is increasing in both $\rho$ and $\beta$. Responding to the lagged interest rate is equivalent to responding to the weighted sum of past and present output gaps and one-step-ahead inflation forecasts. The dependence of policy on current and lagged inflation strengthens the link between expected and actual inflation and thereby reduces the incidence of multiple equilibria. Similarly, because the output gap is proportional to the quasi-difference between the current and expected inflation rate, a positive response to the current output gap is equivalent to raising the response to current inflation and reducing it on expected inflation, and this shift in policy response likewise reduces the incidence of indeterminacy.

Longer-Horizon Forecast Rules. With forecast horizons of two quarters or more, analytical descriptions of the requirements for determinacy are not easily obtained, and hence we compute these conditions numerically. In calibrating the model, we use the parameter values given in Woodford (2000a), simply adjusting these values to account for the fact that our variables are expressed at annual rates. ${ }^{13}$

\footnotetext{
${ }^{12}$ Woodford (2001) refers to this condition as the "Taylor Principle." The increase in the real interest rate dampens aggregate demand, putting downward pressure on inflation. This condition for determinacy also applies to a wide range of macroeconomic models with nominal inertia, including the four larger models considered in this paper. See Bryant, Hooper and Mann, eds (1993), Taylor (1999b), and Levin et al. (1999). In contrast, Christiano and Gust (1999) show that this condition is not sufficient to ensure determinacy in a model with liquidity effects of monetary policy but no nominal inertia. See also Carlstrom and Fuerst (2000) and Benhabib, Schmitt-Grohé and Uribe (2001).

${ }^{13}$ Thus, we set $\delta=0.99, \sigma=1.59$, and $\phi=0.096$, while $r^{*}{ }_{t}$ follows an $\operatorname{AR}(1)$ process with autocorrelation parameter 0.35 and the innovation is i.i.d. with a standard deviation of 3.72 . We assume that the aggregate supply disturbance $\epsilon_{t}$ is i.i.d., and calibrate its standard deviation so that the unconditional variance of inflation under the benchmark rule A matches the sample variance of U.S. quarterly inflation over the period 1983:1-1999:4.
} 
Figure 2: Multiple Equilibria in the Optimizing AD-AS Model

Policy responds to one-quarter inflation rate
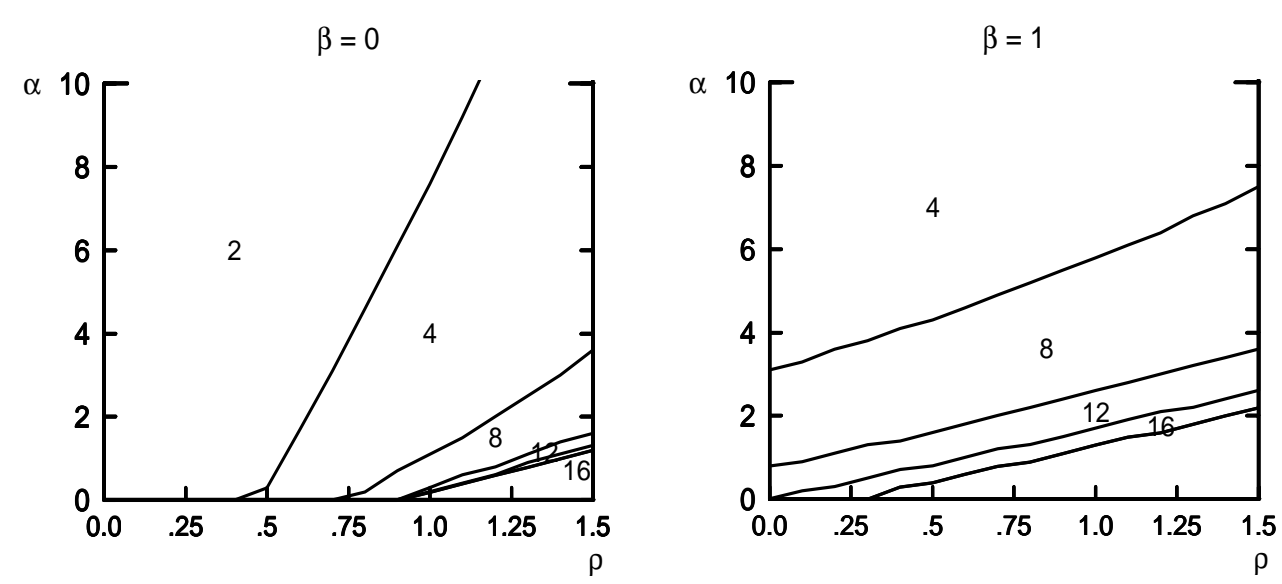

Policy responds to four-quarter inflation rate
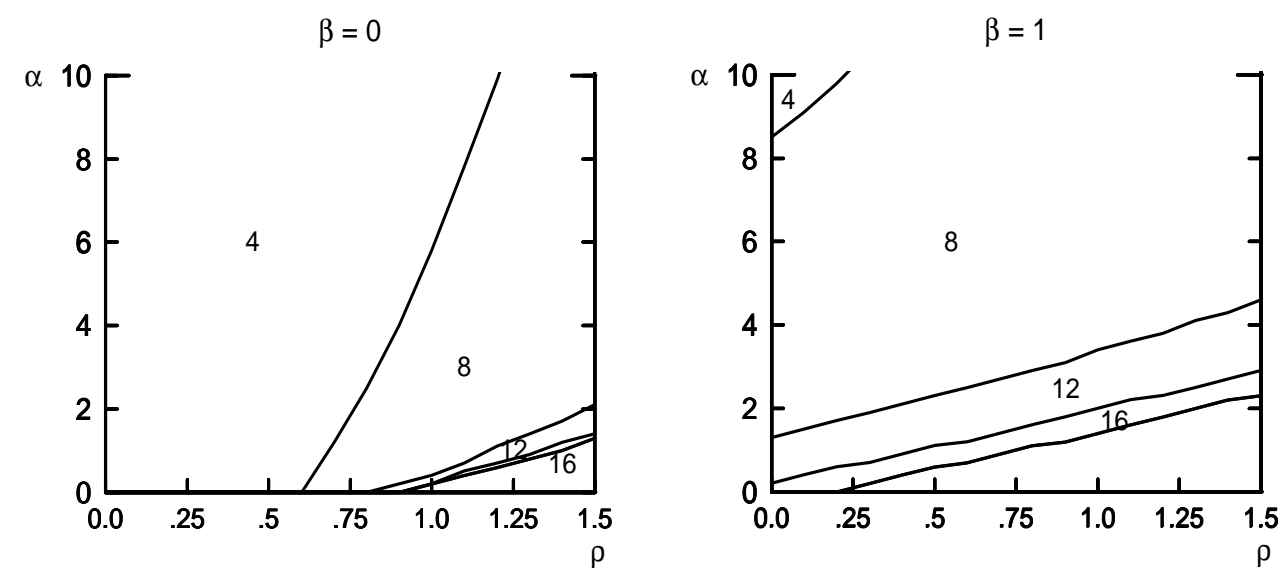

Note: For each specification of the inflation forecast horizon $(2,4,8,12$, and 16 quarters), multiple equilibria occur for all combinations of the parameters $\alpha$ and $\rho$ that lie to the northwest of the corresponding curve. If no curve is shown for a particular forecast horizon, then that specification yields determinacy for all combinations of $0 \leq \alpha \leq 10$ and $0 \leq \rho \leq 1.5$.

Figure 2 shows the conditions under which a given specification of the policy rule generates multiple equilibria in the calibrated model. The upper two panels show results for policy rules involving the one-quarter annualized one-quarter inflation rate $\pi$, while the lower two panels show corresponding results for rules that involve the four-quarter average inflation rate $\tilde{\pi}$. In the two panels on the left side of the figure, policy does not respond explicitly to the output gap; in the two panels on the right, policy exhibits a moderate response to the current output gap (that is, $\beta=1$ and $\kappa=0)$. For each specification of the inflation forecast horizon, the corresponding curve indicates the boundary of the indeterminacy region; that is, multiple equilibria occur for all 
combinations of the parameters $\alpha$ and $\rho$ that lie to the northwest of the specified boundary.

It is evident from Figure 2 that the determinacy conditions for longer-horizon forecasts are qualitatively similar to the analytic conditions discussed above for rules involving one-step-ahead inflation forecasts, and are also systematically related to the choice of inflation measure and to the length of the forecast horizon. For example, the upper-left panel shows that for rules involving $\pi_{t+2}$, no policy inertia $(\rho=0)$, and no response to the output gap $(\beta=0)$, indeterminacy occurs for all positive values of $\alpha$. More generally, we find that:

- Indeterminacy occurs if the policy response to the inflation forecast is sufficiently aggressive for a given inflation measure and positive forecast horizon and for a given amount of policy inertia and output responsiveness. For example, for rules involving $\pi_{t+2}$, moderate policy inertia $(\rho=0.75)$, and no response to the output gap $(\beta=0)$, indeterminacy occurs for all values of $\alpha>4$.

- Determinacy can be obtained by incorporating a sufficiently high degree of policy inertia for any particular choice of inflation measure and forecast horizon and for any given degree of responsiveness to the output gap and to the inflation forecast (subject, of course, to the lowerbound $\alpha>0$ ). For example, setting $\rho=1$ is sufficient to ensure determinacy for any rule involving $\pi_{t+2}$ with $0<\alpha<8$.

- Utilizing a longer inflation forecast horizon expands the region of indeterminacy for either inflation measure. For example, in the upper-left panel, it is evident that setting $\alpha=2$ and $\rho=1$ yields determinacy for rules with a forecast horizon of two quarters but not for rules with a forecast horizon of four quarters or longer.

- Incorporating a explicit response to the current output gap shrinks the range of values of $\alpha$ and $\rho$ that yield indeterminacy for a particular choice of inflation measure and forecast horizon. For example, the upper-right panel shows that a moderate policy response to the current output gap $(\beta=1)$ is sufficient to ensure determinacy for rules involving $\pi_{t+2}$ for all values of $\rho$ and $\alpha$ considered here. While not shown here, it should be emphasized that responding to a forecast of the future output gap (rather than to its current value) does not necessarily help in avoiding indeterminacy, and is even counterproductive in some cases.

- Utilizing a smoothed measure of inflation shrinks the range of values of the policy parameters that yield indeterminacy for a particular choice of forecast horizon. For example, the lower-left panel shows that rules involving the two-step-ahead forecast of the four-quarter average inflation rate $\left(\tilde{\pi}_{t+2}\right)$ yield determinacy for all values of $\alpha$ and $\rho$ considered here, even in the absence of any explicit output response $(\beta=0)$. 
Figure 3: Unconditional Autocorrelations in the Four Macroeconometric Models

Inflation

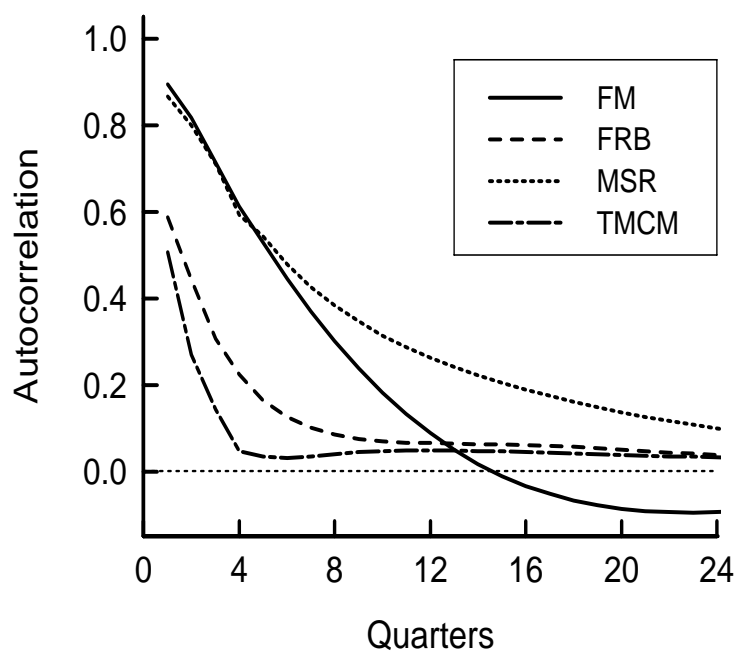

Output Gap

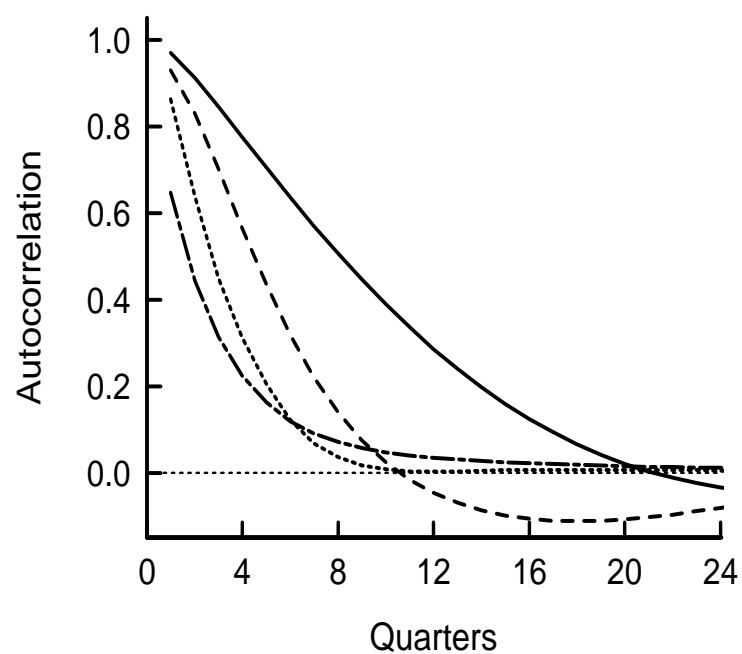

\subsection{Multiple Equilibria in the Four Macroeconometric Models}

The preceding analysis has focused exclusively on the optimizing AD-AS model, in which output and inflation are "jump" variables with no intrinsic inertia. ${ }^{14}$ Now we consider the incidence of indeterminacy in the four macroeconometric models; as noted above, each of these models incorporates rational expectations and exhibits non-negligible persistence of output and inflation.

A measure of the degree of intrinsic persistence in the four models is provided by Figure 3, which shows the unconditional autocorrelations of inflation and the output gap. ${ }^{15}$ For these computations, we assume monetary policy follows the benchmark policy rule A given in equation (1). Consistent with the verbal description in the previous section (and the more detailed discussion in the Appendix), inflation is highly persistent in the FM and MSR models and far less so in the FRB and TMCM models; the output gap is also much more persistent in the FM model than in the other three macroeconometric models.

Now we follow the same approach as in the previous subsection in analyzing the conditions on forecast-based rules that are required to obtain determinacy in each model. We find that the FM model is relatively immune to indeterminacy problems: even with a forecast horizon of 16 quarters and no explicit response to the output gap, all combinations of $0<\alpha \leq 10$ and $0 \leq \rho \leq 1.5$ are

\footnotetext{
${ }^{14}$ Fuhrer and Moore (1995) and Estrella and Fuhrer (1998) have criticized this lack of intrinsic inertia as being at odds with the data. For other views on this issue, see the published discussions of Fuhrer (1997b) and Rotemberg and Woodford (1997), as well as the recent analysis of Erceg and Levin (2000).

${ }^{15}$ Autocorrelations provide a reasonable measure of intrinsic persistence for these four models because nearly all the shocks used for computing unconditional moments are serially uncorrelated; the only exceptions are the term premium shocks for certain financial variables in FRB and TMCM.
} 
Figure 4: Cross-Model Comparison of Indeterminacy Regions: $\beta=0$

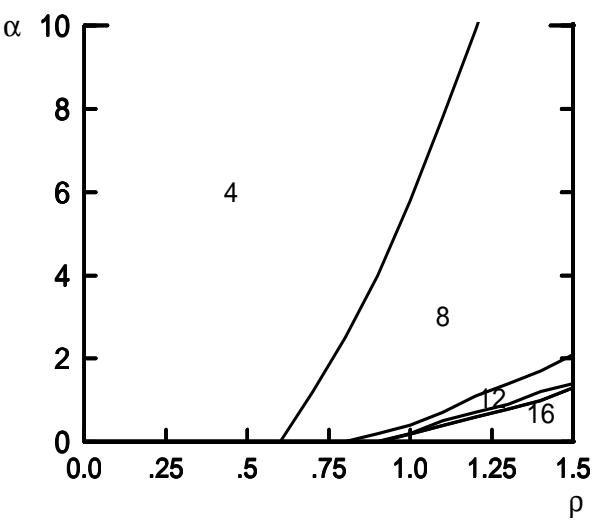

MSR

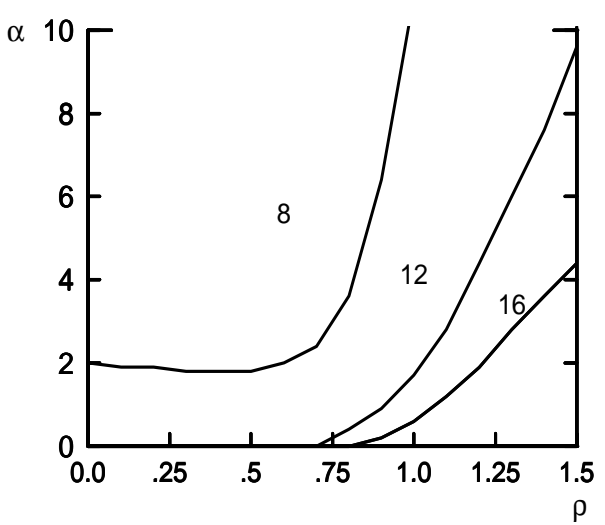

$\alpha$

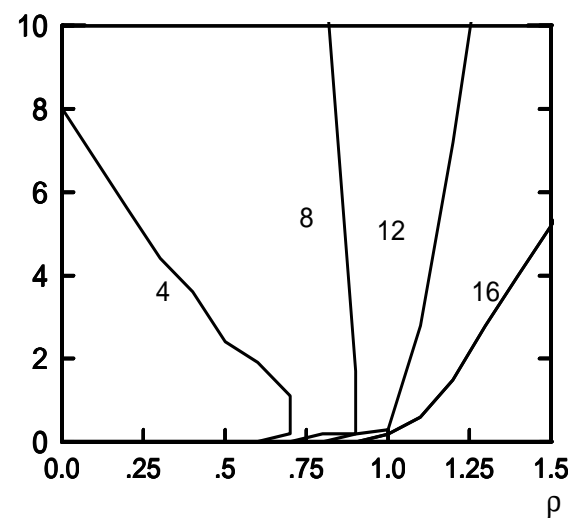

TMCM

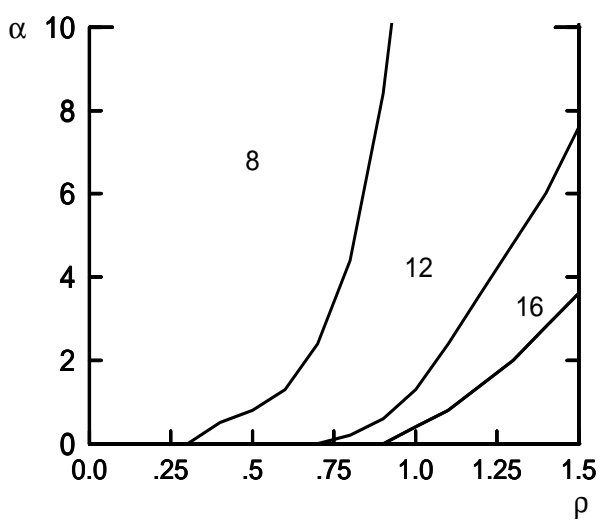

Note: See Figure 2.

consistent with a unique rational expectations equilibrium. This result follows directly from the highly persistent nature of output and inflation in the FM model, because this persistence implies a close correspondence between the current inflation rate and its expected value several years hence.

In contrast, the determinacy conditions for the FRB, MSR and TMCM models are qualitatively similar to those of the small stylized model; quantitatively, these conditions depend on the specific output and price dynamics of each model. In particular, Figure 4 shows the indeterminacy boundaries for forecast-based rules that utilize the four-quarter average inflation rate and that do not respond directly to the output gap. For purposes of comparison with the optimizing AD-AS model, the relevant panel from Figure 2 is shown again here.

As in the previous analysis, we find that the indeterminacy region expands with the length of 
Figure 5: Cross-Model Comparison of Indeterminacy Regions: $\beta=1$

Optimizing AD-AS

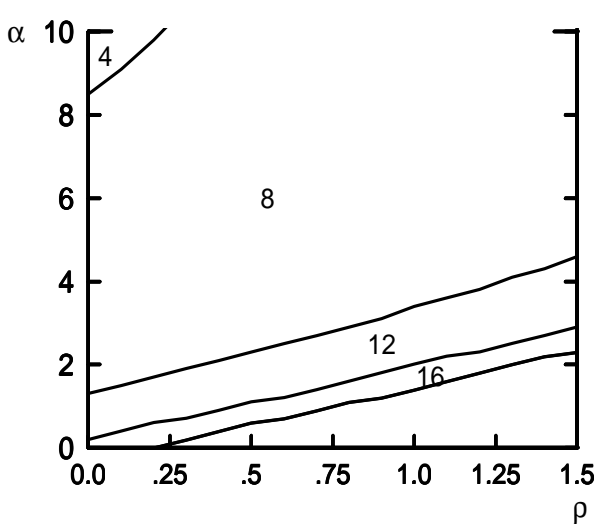

MSR

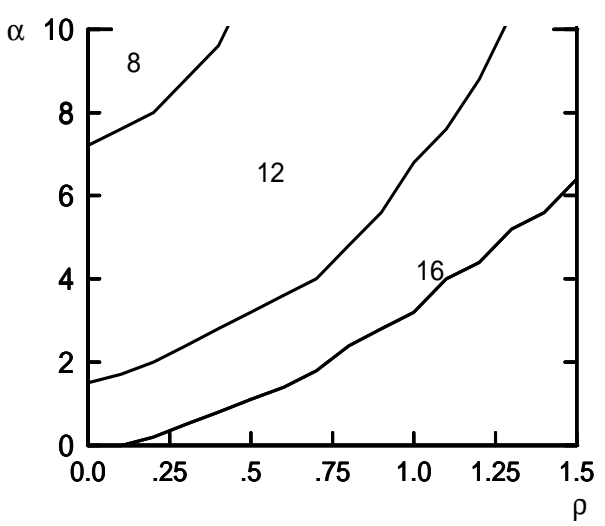

FRB

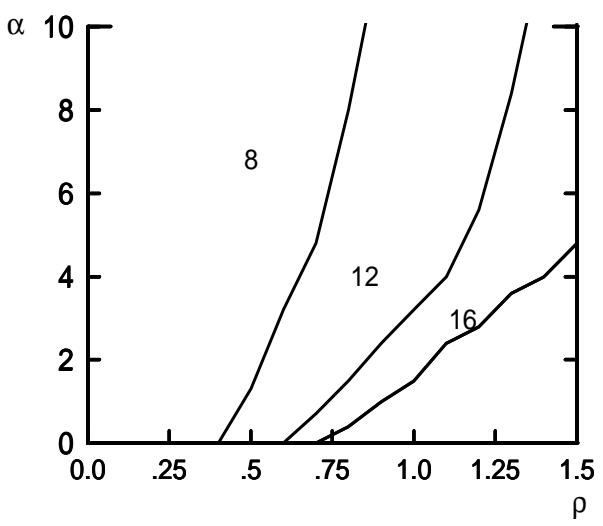

TMCM

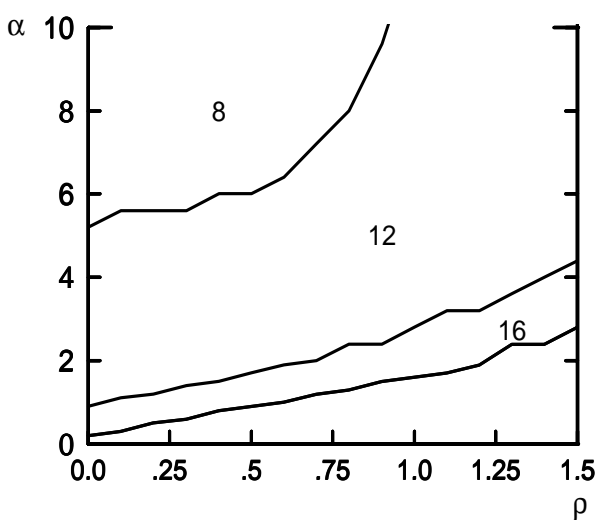

Note: See Figure 2.

the inflation forecast horizon and that the incidence of indeterminacy shrinks with the degree of interest rate smoothing. For example, in three of the macroeconometric models, as in the optimizing AD-AS model, an inflation forecast horizon of 16 quarters generates multiple equilibria for virtually all combinations of $0<\alpha \leq 10$ and $0 \leq \rho \leq 1$. For rules involving a four-quarter inflation forecast horizon, determinacy occurs in the MSR and TMCM models for all combinations of $\alpha$ and $\rho$ shown in the figure; in the FRB model, $\rho>0.75$ is sufficient to ensure determinacy for all $0<\alpha \leq 10 .{ }^{16}$

Allowing for a moderate response to the current output gap shrinks the region of indeterminacy in each macroeconometric model. Figure 5 shows the indeterminacy boundaries for rules with a

\footnotetext{
${ }^{16}$ Although not shown in Figures 4 and 5, indeterminacy arises in each of the macroeconometric models if $\alpha$ is very close to zero, especially with long forecast horizons; this lower bound is typically on the order of 0.1 .
} 
unit coefficient on the current output gap (that is, $\beta=1$ ). ${ }^{17}$ With this output response, rules that utilize an four-quarter inflation forecast horizon yield a unique equilibrium in every model for every combination of $0<\alpha \leq 8$ and $0 \leq \rho \leq 1.5$. Finally, while not shown here, we have also computed indeterminacy regions for each of the four macroeconometric models for policy rules that involve the annualized one-quarter inflation rate $\pi$ instead of the annual average inflation rate $\tilde{\pi}$; as in the previous subsection, we find that using the smoothed inflation measure shrinks the indeterminacy region in each model (especially for shorter forecast horizons).

\subsection{Behavior of Forecast-Based Rules from the Literature}

Now we examine how the forecast-based rules given in Table 1 fare in terms of determinacy. Our analysis has highlighted several key characteristics of rules that yield a unique equilibrium in every model: a relatively short inflation forecast horizon; a smoothed measure of inflation (that is, the four-quarter average rather than the annualized one-quarter rate); a moderate degree of responsiveness to the inflation forecast $(0<\alpha<5)$; an explicit response to the current output gap $(\beta>0)$; and a substantial degree of policy inertia $(\rho \geq 0.5)$. Thus, the first five columns of Table 2 indicate the extent to which each rule exhibits these properties, while each of the remaining columns indicate whether the rule generates multiple equilibria ("ME") or determinacy ("-") in the specified model. As shown in the first row of the table, the benchmark outcome-based rule A satisfies the lower bound $\alpha>0$, and hence yields a unique stationary equilibrium in all five models.

Among the forecast-based policy rules, it is striking that only rules B and E yield determinacy in every model. Rule B possesses all the characteristics supportive of determinacy, including the use of a smoothed measure of inflation, a four-quarter inflation forecast horizon, a positive output gap response, and a substantial degree of policy inertia. While rule E does not respond explicitly to the output gap, this rule does incorporate a high degree of policy inertia and utilizes a short inflation forecast horizon of only two quarters.

Rules $\mathrm{C}$ and $\mathrm{D}$ generate multiple equilibria in the optimizing AD-AS model but not in any of the macroeconometric models. Compared with rule B, the degree of policy inertia is much lower for rule $\mathrm{C}$ and is completely absent from rule $\mathrm{D}$. These two rules also differ from rule $\mathrm{B}$ in responding to the four-quarter-ahead forecast of the output gap rather than to its current value. Given the absence of intrinsic output and inflation inertia in the optimizing AD-AS model, responding to the one-year-ahead projected output gap does not contribute toward ensuring determinacy in this model, whereas such a response does facilitate determinacy in each of the four macroeconometric models. We will return to this issue in Section 5.3 when we consider the stabilization performance of rules involving output gap forecasts.

Rules F, G, H, I, J, and K generate multiple equilibria in the optimizing AD-AS model and

\footnotetext{
${ }^{17}$ We have explored these indeterminacy regions for other values of $\beta$ and obtained qualitatively similar results.
} 
Table 2: Determinacy of Rules from the Literature

\begin{tabular}{|c|c|c|c|c|c|c|c|c|c|c|}
\hline \multirow[t]{2}{*}{ Rule } & \multicolumn{5}{|c|}{ Policy Rule Characteristics } & \multicolumn{5}{|c|}{ Model } \\
\hline & $\begin{array}{l}\text { Inflation } \\
\text { Forecast } \\
\text { Horizon }\end{array}$ & $\begin{array}{l}\text { Smoothed } \\
\text { Inflation } \\
\text { Measure }\end{array}$ & $\alpha$ & $\beta$ & $\rho$ & $\begin{array}{c}\text { Opt. } \\
\text { AD-AS }\end{array}$ & FM & FRB & MSR & TMCM \\
\hline $\mathrm{A}$ & 0 & $\mathrm{X}$ & .4 & .2 & .8 & - & - & - & - & - \\
\hline $\mathrm{B}$ & 4 & $\mathrm{X}$ & .3 & .1 & .8 & - & - & - & - & - \\
\hline $\mathrm{C}$ & 4 & $\mathrm{X}$ & .3 & .4 & .6 & ME & - & - & - & - \\
\hline $\mathrm{D}$ & 4 & $\mathrm{X}$ & 2.8 & 1.0 & - & $\mathrm{ME}$ & - & - & - & - \\
\hline $\mathrm{E}$ & 2 & - & 1.3 & - & 1.0 & - & - & - & - & - \\
\hline $\mathrm{F}$ & $3-4$ & $\mathrm{X}$ & 1.5 & - & - & ME & - & $\mathrm{ME}$ & - & - \\
\hline $\mathrm{G}$ & 8 & - & 2.0 & - & .6 & $\mathrm{ME}$ & - & $\mathrm{ME}$ & $\mathrm{ME}$ & - \\
\hline $\mathrm{H}$ & 12 & - & 3.6 & - & .7 & $\mathrm{ME}$ & - & $\mathrm{ME}$ & $\mathrm{ME}$ & - \\
\hline I & 15 & - & 34.8 & - & .8 & $\mathrm{ME}$ & $\mathrm{ME}$ & $\mathrm{ME}$ & $\mathrm{ME}$ & $\mathrm{ME}$ \\
\hline $\mathrm{J}$ & 8 & $\mathrm{X}$ & 3.0 & - & - & $\mathrm{ME}$ & - & $\mathrm{ME}$ & $\mathrm{ME}$ & $\mathrm{ME}$ \\
\hline $\mathrm{K}$ & 8 & - & 0.5 & - & .5 & $\mathrm{ME}$ & - & $\mathrm{ME}$ & - & - \\
\hline
\end{tabular}

Notes: In the column labelled "Smoothed Inflation Measure", "X" signifies that the rule utilizes the four-quarter average inflation rate, while "-" indicates that the rule utilizes the one-quarter annualized inflation rate. In the last five columns, "ME" signifies that the rule yields multiple equilibria in the specified model, while "-" indicates that the rule yields a unique stationary equilibrium.

in at least one of the macroeconometric models. It is notable that none of these rules includes an explicit response to the output gap. Furthermore, five of the six rules utilize an inflation forecast horizon of at least eight quarters; the exception is rule $\mathrm{F}$, which has a shorter forecast horizon but suffers from a complete lack of policy inertia. Finally, rule I is unique in generating indeterminacy in the FM model, which has the greatest degree of intrinsic inertia among the models considered here; this outcome occurs because rule I utilizes a forecast horizon of nearly four years along with an exceptionally high value of $\alpha=34.8$ (far outside the range considered in the preceding figures).

These results indicate that the issue of indeterminacy is relevant not only in small "stylized" models but also in macroeconometric models that exhibit a higher degree of inflation and output persistence. In particular, a number of policy rules proposed in the literature fail to ensure a unique stationary equilibrium in at least one of the four macroeconometric models considered here. Thus, the characteristics listed above are crucial in identifying forecast-based rules that are likely to be robust to model uncertainty. 


\section{Optimized Forecast-Based Rules}

In this section, we investigate the characteristics of optimized forecast-based rules. In light of the results of the previous section, we restrict our attention to rules that yield a unique rational expectations equilibrium in the specified model. ${ }^{18}$ For a given model and a specific form of the policy rule, we determine the inflation and output gap forecast horizons and coefficients that minimize a weighted average of inflation variability and output gap variability, subject to an upper bound on interest rate variability.

\subsection{The Optimization Problem}

We assume that the policymaker's loss function $\mathcal{L}$ has the form

$$
\mathcal{L}=\operatorname{Var}(\pi)+\lambda \operatorname{Var}(y)
$$

where $\operatorname{Var}($.$) denotes the unconditional variance and the weight \lambda \geq 0$ indicates the policymaker's preference for reducing output variability relative to inflation variability. For example, $\lambda=1 / 3$ may be viewed as representing a policymaker who is primarily concerned with stabilizing inflation but who also places some weight on stabilizing the output gap, whereas $\lambda=0$ represents a policymaker whose sole objective is to minimize inflation variability (that is, an "inflation nutter" in the terminology of King (1997)). For a given value of $\lambda$ and a particular functional form of the policy rule, the parameters of the rule are chosen to minimize the loss function $\mathcal{L}$ subject to an upper bound on the volatility of changes in the short-term nominal interest rate; that is, the unconditional standard deviation of $\Delta i_{t}$ cannot exceed a specified value $\bar{\sigma}_{\Delta i}$.

Henceforth we consider linear policy rules of the general form given by equation (2). ${ }^{19}$ As in the previous section, we consider two alternatives for the inflation measure $\bar{\pi}$. When the policy rule utilizes the annualized one-quarter inflation rate, $\pi$, we refer to this specification as the class of $F B 1$ rules. When the rule utilizes the four-quarter average inflation rate, $\tilde{\pi}$, we refer to this specification as the class of $F B 4$ rules. We also consider the more restricted class of $F B 4 X G$ rules that exclude an explicit output gap response (that is, $\beta \equiv 0$ ). Finally, we refer to outcome-based rules (in which the forecast horizons $\theta=\kappa=0$ ) as the class of OB rules.

\footnotetext{
${ }^{18}$ In nearly all cases, this restriction is not binding in the sense that the optimal rules we consider are well away from the regions of indeterminacy. In the few cases where the constraint is binding, we make note of that fact.

${ }^{19}$ Given the assumption of a quadratic objective function and the linear structure of each model, the restriction to linear rules is innocuous and greatly facilitates computation. More generally, non-quadratic preferences or model nonlinearities give rise to nonlinear optimal policy rules (cf. Orphanides and Wilcox (1996), Orphanides, Small, Wieland and Wilcox (1997), Isard, Laxton and Eliasson (1999)). For example, explicit inflation-targeting regimes typically are implemented with respect to a target zone rather than a specific target point, implying a nonlinear policy response (Orphanides and Wieland (1999), Tetlow (2000)). Furthermore, the presence of the non-negativity constraint on nominal interest rates directly imposes a nonlinearity to the policy rule (Fuhrer and Madigan (1997), Orphanides and Wieland (1998), Wolman (1998), Reifschneider and Williams (2000)). In the present paper, we do not investigate the extent to which nonlinear policy rules are sensitive to model uncertainty, but rather leave this issue for future research.
} 
All five models considered in this paper exhibit a tradeoff between inflation-output variability and interest rate variability, except at very high levels of interest rate variability. ${ }^{20}$ Figure 6 illustrates this tradeoff for the four macroeconometric models for three values of the policy preference parameter $\lambda$. In particular, for each model, we consider the set of OB rules of the form given by equation (2) for which the coefficients $\rho, \alpha$, and $\beta$ are chosen optimally given that the forecast horizons $\theta=\kappa=0$. For a specific value of $\lambda$, each point on the corresponding curve indicates the minimized value of the loss function $\mathcal{L}$ for a particular value of $\bar{\sigma}_{\Delta i}$. The vertical line in each panel indicates the standard deviation of interest rate changes associated with the benchmark estimated rule $\mathrm{A}$; this value varies noticeably across the four models, mainly due to the use of a different sample period in estimating the parameters and the innovation covariance matrix of each model (cf. Appendix Table A1). ${ }^{21}$

From Figure 6 it is evident that stabilization performance deteriorates rapidly if interest rate volatility is constrained to be much lower than that induced by rule A (which was estimated over the period 1980-1998). On the other hand, stabilization performance cannot be substantially improved even if interest rate volatility is permitted to be much higher than that induced by rule A (unless the policymaker places implausibly high weight on output volatility). ${ }^{22}$ Therefore, we focus our attention on policy rules for which the parameters are chosen to minimize the loss function $\mathcal{L}$ subject to the constraint that interest rate volatility cannot exceed that of rule A.

\subsection{Characteristics of Optimized Rules}

We now analyze the optimal choices of forecast horizons and policy rule coefficients for each model for a range of values of the preference parameter $\lambda$. In particular, we consider a relatively large grid of possible combinations of inflation and output forecast horizons. For each point on this grid, we compute the values of the policy rule coefficients that minimize the loss function $\mathcal{L}$ subject to the specified upper bound on interest rate volatility. Finally, we compare the resulting values of $\mathcal{L}$ across the forecast horizon grid to determine the optimal combination of inflation and output forecast horizons. We only consider forecast horizons up to 20 quarters for both the inflation rate and the output gap; however, this constraint binds only in one case noted below.

For each model and each value of $\lambda$, the first three columns of Table 3 indicate the optimal values of $\theta$ and $\kappa$ for the class of FB4 rules and the percent change in the loss function - denoted

\footnotetext{
${ }^{20}$ This tradeoff is characteristic of many macroeconomic models in the recent literature; cf. the papers in Taylor, ed (1999), and further discussion in Sack and Wieland (2000).

${ }^{21}$ In evaluating the performance of rule A, we set its innovation variance to zero.

${ }^{22}$ We also note that a linear policy rule which induces highly variable nominal interest rates may not be implementable in practice, because such a rule will prescribe frequent (and occasionally large) violations of the nonnegativity constraint on the federal funds rate (cf. Rotemberg and Woodford (1999)). In principle, we could analyze nonlinear rules that incorporate this non-negativity constraint (see Orphanides and Wieland (1998), Reifschneider and Williams (2000), and Wolman (1998)), but doing so would substantially increase the computational costs of our analysis.
} 
Figure 6: The Tradeoff between Interest Rate Variability and Macroeconomic Stabilization

FM

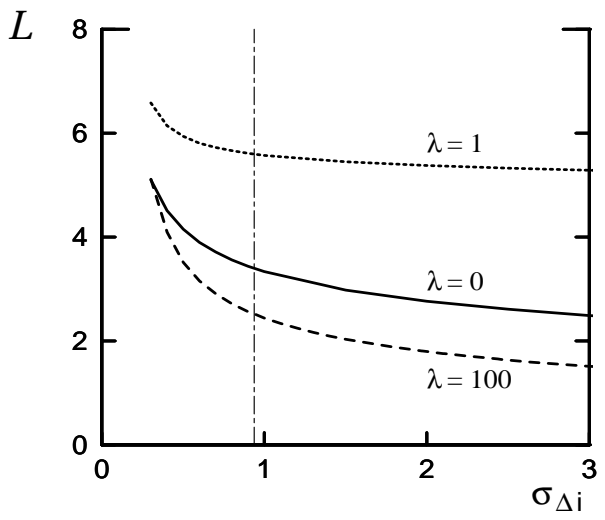

MSR

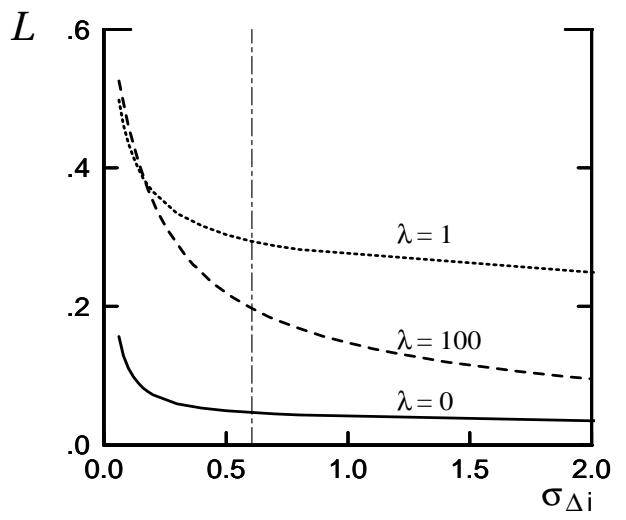

FRB

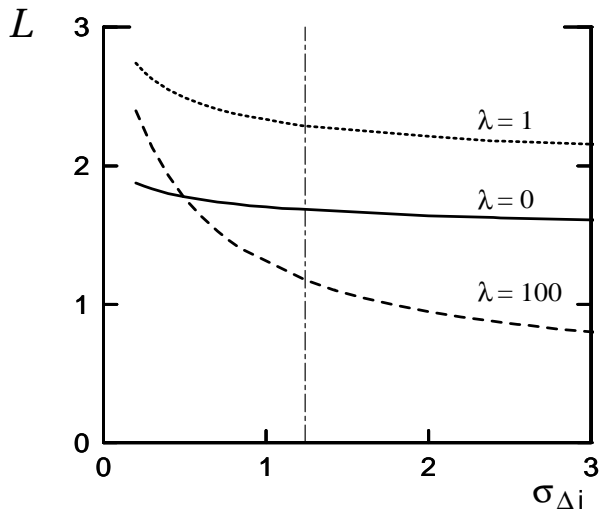

TMCM

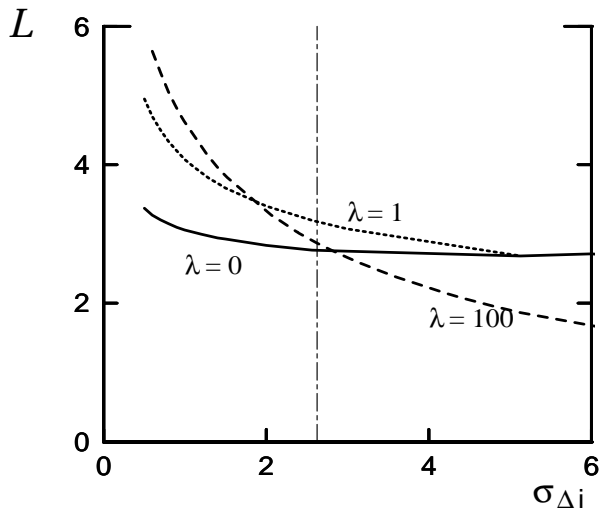

Note: The vertical dash-dot line indicates the value of $\sigma_{\Delta i}$ generated by the benchmark rule A.

$\% \Delta \mathcal{L}$ - relative to the optimized $\mathrm{OB}$ rule. Note that $\% \Delta \mathcal{L}$ is always non-positive for FB4 rules because the class of OB rules (for which $\theta=\kappa=0$ ) is nested within the class of FB4 rules. The remaining columns of the table indicate the corresponding results for the class of FB1 rules and for the class of FB4XG rules. (The coefficients $\rho, \alpha$, and $\beta$ of each optimized rule are reported in Appendix Table A2.)

The first notable result in Table 3 is that the optimal inflation and output gap forecast horizons are generally very short for FB4 rules. In the optimizing AD-AS model, outcome-based rules (with $\theta=\kappa=0$ ) generally outperform rules with any positive forecast horizon. This result may not be surprising given the lack of intrinsic inertia in this model. Nevertheless, even in the four macroeconometric models, the optimal forecast horizons never exceed four quarters. When the policymaker's loss function involves both inflation variability and output gap variability (that is, when $\lambda>0$ ), the optimal values of $\theta$ and $\kappa$ are only 0-2 quarters in the FRB, MSR and TMCM 
Table 3: Optimal Forecast Horizons and Stabilization Performance

\begin{tabular}{|c|c|c|c|c|c|c|c|c|c|c|}
\hline \multirow[b]{2}{*}{ Model } & \multirow[b]{2}{*}{$\lambda$} & \multicolumn{3}{|c|}{ FB4 Rules } & \multicolumn{3}{|c|}{ FB1 Rules } & \multicolumn{3}{|c|}{ FB4XG Rules } \\
\hline & & $\theta$ & $\kappa$ & $\% \Delta \mathcal{L}$ & $\theta$ & $\kappa$ & $\% \Delta \mathcal{L}$ & $\theta$ & $\kappa$ & $\% \Delta \mathcal{L}$ \\
\hline \multirow{4}{*}{$\begin{array}{l}\text { Opt. } \\
\text { AD-AS }\end{array}$} & 0 & 0 & 1 & -20 & 0 & 0 & 18 & 0 & - & 0 \\
\hline & $1 / 3$ & 0 & 0 & 0 & 0 & 0 & 6 & 2 & - & 734 \\
\hline & 1 & 0 & 0 & 0 & 0 & 0 & 2 & 2 & - & 2721 \\
\hline & 3 & 0 & 0 & 0 & 0 & 0 & 1 & 2 & - & 3216 \\
\hline \multirow{4}{*}{ FM } & 0 & 1 & 0 & -0 & 0 & 0 & 0 & 9 & - & 1 \\
\hline & $1 / 3$ & 0 & 4 & -1 & 0 & 7 & 0 & 18 & - & 2 \\
\hline & 1 & 0 & 4 & -1 & 0 & 7 & 0 & 18 & - & 11 \\
\hline & 3 & 0 & 4 & -1 & 0 & 7 & 1 & 20 & - & 30 \\
\hline \multirow{4}{*}{ FRB } & 0 & 4 & 1 & -10 & 2 & 0 & -9 & 4 & - & -10 \\
\hline & $1 / 3$ & 0 & 2 & -5 & 1 & 3 & -4 & 7 & - & 167 \\
\hline & 1 & 0 & 2 & -7 & 1 & 3 & -6 & 8 & - & 407 \\
\hline & 3 & 0 & 2 & -9 & 1 & 3 & -8 & 8 & - & 793 \\
\hline \multirow{4}{*}{ MSR } & 0 & 0 & 0 & 0 & 0 & 0 & 7 & 0 & - & 0 \\
\hline & $1 / 3$ & 0 & 1 & -3 & 1 & 1 & 3 & 5 & - & 117 \\
\hline & 1 & 0 & 1 & -3 & 1 & 1 & 2 & 4 & - & 195 \\
\hline & 3 & 0 & 1 & -1 & 1 & 1 & 1 & 4 & - & 295 \\
\hline \multirow{4}{*}{ TMCM } & 0 & 2 & 0 & -4 & 1 & 1 & -4 & 3 & - & -4 \\
\hline & $1 / 3$ & 2 & 0 & -0 & 1 & 0 & -0 & 3 & - & 24 \\
\hline & 1 & 1 & 1 & -0 & 1 & 0 & -0 & 3 & - & 55 \\
\hline & 3 & 1 & 1 & -1 & 1 & 1 & -1 & 6 & - & 87 \\
\hline
\end{tabular}

Notes: For each model, each value of the preference parameter $\lambda$, and each specification of the policy rule, this table indicates the optimal inflation and output gap forecast horizons $(\theta$ and $\kappa)$ and the percentage point change in the policymaker's loss function $(\% \Delta \mathcal{L})$ compared with the optimized outcome-based (OB) rule (for which $\theta \equiv \kappa \equiv 0$ ). FB4 rules utilize the four-quarter average inflation rate $\tilde{\pi}$, while FB1 rules utilize the one-quarter annualized inflation rate $\pi$; FB4XG rules have no explicit response to the output gap $(\beta \equiv 0)$. 
models; for the FM model, the optimal horizons are $\theta=0$ and $\kappa=4$.

The optimal forecast horizons for FB1 rules are somewhat longer, especially for the FM model (where $\kappa=7$ when $\lambda>0$ ). The optimal inflation forecast horizon are also longer for FB4XG rules, and in some cases, markedly so. For example, with $\lambda=1$, the optimal inflation forecast horizon is 8 quarters for the FRB model and 18 quarters for the FM model. ${ }^{23}$

A second striking result in Table 3 is that forecast-based rules never yield dramatic improvements in stabilization performance compared with that of simple outcome-based rules. For FB4 rules, the reduction in the policymaker's loss function never exceeds 20 percent, and is less than 5 percent for all values of $\lambda$ in three of the models (FM, MSR, and TMCM). Furthermore, these results do not depend on the choice of inflation measure: in fact, FB1 rules typically perform slightly worse than FB4 rules. Finally, although not shown in the table, we have confirmed that these results are not sensitive to the particular choice of upper bound on interest rate variability. ${ }^{24}$

Evidently, some of the purported advantages of forecast-based rules (such as "lag encompassing" and "information encompassing") are quantitatively unimportant, even in rational expectations models with substantial transmission lags and complex dynamic properties. These results are consistent with those of Levin et al. (1999), who found that fairly complicated outcome-based rules (which respond to a large number of observable state variables) yield only small stabilization gains over simple outcome-based rules. It is also interesting to note that Rudebusch and Svensson (1999) found similar results in a small macroeconometric model with adaptive expectations: although the Rudebusch-Svensson model includes a dozen state variables, the current output gap and fourquarter average inflation rate essentially serve as sufficient statistics for monetary policy, and hence forecast-based rules provide minimal stabilization gains even in that model.

Finally, it has been argued that a rule which responds exclusively to the inflation forecast (with a suitable choice of forecast horizon) can be effective at stabilizing both output and inflation, even without an explicit response to the output gap. As shown in the final column of Table 3, FB4XG rules do perform as well as the more general FB4 rules when the policymaker's objective function places no weight on output gap variability $(\lambda=0)$. However, when the policymaker's loss function places non-trivial weight on output gap variability, then excluding the output gap from the policy rule can cause a severe deterioration in stabilization performance. For example, when $\lambda=1 / 3$, FB4XG rules generate excess losses (compared with OB rules) of over 100 percent in the FRB and MSR models and over 700 percent in the optimizing AD-AS model. Thus, "output encompassing" is not a general characteristic of inflation forecast rules. ${ }^{25}$

\footnotetext{
${ }^{23}$ As noted above, we restricted our search to forecast horizons up to 20 quarters; this bound is only reached in one case, namely, the inflation forecast horizon for the FM model when $\lambda=3$.

${ }^{24}$ We have repeated the analysis described above using an upper bound $\bar{\sigma}_{\Delta i}$ that is twice as large as the value associated with rule A. Relaxing this constraint yields small improvements in stabilization performance, but the relative performance of forecast-based to outcome-based policy rules does not change significantly.

${ }^{25}$ Our analysis assumes that the output gap is known in real time, whereas in practice the output gap may be
} 


\section{Robustness of Optimized Rules under Model Uncertainty}

Now we analyze the extent to which optimized forecast-based rules are robust to model uncertainty. As we have seen, the optimal forecast horizons are only 0-1 quarters for FB4 rules in the optimizing AD-AS model. In this section, therefore, we focus our attention on the properties of the optimized forecast-based rules taken from each of the four macroeconometric models (FM, FRB, MSR, and TMCM). Our approach is to assume that the parameters of the policy rule are optimized based on one of the four macroeconometric models, whereas the true economy is described by a different model; that is, the model used for choosing the policy rule is misspecified.

In the context of forecast-based policies, we need to make a further assumption regarding how expectations are formed in implementing the policy rule. First, we consider the "model consistent" case in which the policymaker's forecasts are based on the true model; that is, the forecasts are unbiased and efficient. Next, we consider the "model inconsistent" case in which the forecasts are constructed from the same misspecified model that has been used for determining the parameters of the policy rule. In the first case, macroeconomic performance suffers because of the suboptimal choice of policy rule parameters; in the second case, systematic forecast errors are added to the problem. While we could consider other variants on model-inconsistent forecasts (such as generating forecasts from a VAR model), we believe that such variants would not substantially change the results reported here.

Our basic method for evaluating robustness is the same for both cases of forecast generation. For a given value of the policy preference parameter $\lambda$, we take a given rule $\mathrm{X}$ that has been optimized for a specific model - referred to as the "rule-generating" model - and we simulate rule $\mathrm{X}$ in a different model - referred to as the "true economy" model. If rule $\mathrm{X}$ generates a unique rational expectations equilibrium, then we compute its loss function $\mathcal{L}$ (using the specified value of $\lambda$ ). Now we evaluate the robustness of rule $\mathrm{X}$ by comparing its performance with the appropriate outcome-based (OB) policy frontier of the true economy model. Thus, we find the OB policy rule $\mathrm{Y}$ that has been optimized for the true economy model subject to the constraint that its interest rate volatility $\left(\sigma_{\Delta i}\right)$ cannot exceed that implied by rule X. Finally, we compute $\% \Delta \mathcal{L}$, the relative deviation (in percentage points) of the loss function value of rule $\mathrm{X}$ from that of rule $\mathrm{Y}$, that is, $\% \Delta \mathcal{L}$ measures the relative distance of the loss function of rule $\mathrm{X}$ from the relevant $\mathrm{OB}$ policy frontier in Figure 6.

subject to persistent measurement errors (cf. Orphanides (1998a)). Still, the existence of output gap mismeasurement does not imply that policy should completely exclude a response to the output gap. In a linear-quadratic framework with symmetric information, the optimal response to the efficent output gap estimate is invariant to the degree of mismeasurement (cf. Svensson and Woodford (2000)). For simple outcome-based rules, output gap mismeasurement does imply some attenuation - but not complete elimination - of the output gap response (Smets (1999), Orphanides (1998b), Swanson (2000), Orphanides, Finan, Porter, Reifschneider and Tetlow (2000)). 


\subsection{Robustness with Model-Consistent Forecasts}

In this subsection, we assume that the policy rule is optimized using a misspecified model, but the central bank uses model-consistent forecasts of inflation and output; that is, these forecasts are formulated using the true model of the economy with the actual policy rule in operation. This exercise might be motivated as follows. Suppose that a policymaker develops a forecast-based rule that is optimal in the particular modeling framework that the policymaker prefers to use for this purpose; unfortunately, this model is an imperfect representation of the true economy. The policymaker decides to use the optimized rule to implement monetary policy and communicates this intention to the central bank staff. In implementing the policy rule, the policymaker is willing to use forecasts that are generated using the staff's macroeconometric model; coincidentally, this model happens to be the correct representation of the true economy. In the following section we consider the case in which the central bank staff generates its forecasts using the same (misspecified) model that the policymaker used in choosing the policy rule. ${ }^{26}$

Table 4 reports on the robustness to model uncertainty of each class of policy rules. In the top half of the table, the first three columns indicate the degree of robustness of rules that have been optimized for the FM model, while the last three columns indicate the performance of rules that have been optimized for the FRB model. In the lower half of the table, the first three columns refer to rules optimized for the MSR model, while the final three columns refer to rules optimized for the TMCM model.

One striking result in Table 4 is that optimized FB4 rules are remarkably robust to model uncertainty. For example, all of the optimized FB4 rules from the other models lie very close to the OB policy frontier of the TMCM model; in fact, in a few cases, an optimized FB4 rule from another model slightly outperforms the OB rule that is optimized for TMCM. In all cases in all four models, the relative loss from using an optimized FB4 rule never exceeds 70 percent.

In most cases, optimized FB1 rules utilize forecast horizons similar to those of optimized FB4 rules (namely, 0-4 quarters) and yield fairly similar robustness results. The notable exception is the set of FB1 rules optimized for the FM model with $\lambda>0$ : each of these rules involves a substantially longer output gap forecast horizon of 7 quarters. Two of these rules yield indeterminacy in the MSR model, while the third yields a relative loss of over 90 percent; these rules also perform relatively poorly in the FRB and TMCM models.

Finally, Table 4 shows that optimized FB4XG rules are subject to disastrous performance in the face of model uncertainty. Apart from the case of $\lambda=0$ (for which FB4XG rules are virtually

\footnotetext{
${ }^{26}$ We do not analyze the performance of rules involving forecasts based on an exogenous or unchanged path for the nominal interest rate; such an approach has been studied by Rudebusch and Svensson (1999). While constantinterest-rate forecasts can serve to highlight the risks associated with policy inaction, such forecasts ignore relevant information on the central bank's systematic future policy response, and are particularly problematic in rational expectations models, in which permanently fixed nominal interest rates generate indeterminacy.
} 
Table 4: Robustness of Optimized Rules with Model-Consistent Forecasts

\begin{tabular}{|c|c|c|c|c|c|c|c|}
\hline \multirow{2}{*}{$\begin{array}{l}\text { Policy Rule } \\
\text { Specification }\end{array}$} & \multirow[b]{2}{*}{$\lambda$} & \multicolumn{3}{|c|}{ Optimized for FM } & \multicolumn{3}{|c|}{ Optimized for FRB } \\
\hline & & FRB & MSR & TMCM & $\mathrm{FM}$ & MSR & TMCM \\
\hline \multirow{4}{*}{ FB4 } & 0 & 7 & 40 & -0 & 65 & 16 & -2 \\
\hline & $1 / 3$ & 5 & 27 & 12 & 6 & 2 & 2 \\
\hline & 1 & 9 & 41 & 11 & 9 & 5 & 0 \\
\hline & 3 & 16 & 57 & 9 & 14 & 9 & -1 \\
\hline \multirow{4}{*}{ FB1 } & 0 & 12 & 54 & 5 & 56 & 22 & $\overline{-1}$ \\
\hline & $1 / 3$ & 23 & 91 & 54 & 9 & 8 & 3 \\
\hline & 1 & 37 & $\mathrm{ME}$ & 86 & 10 & 14 & 4 \\
\hline & 3 & 42 & $\mathrm{ME}$ & 70 & 13 & 20 & 3 \\
\hline \multirow{4}{*}{ FB4XG } & 0 & 6 & 13 & 23 & 65 & 16 & -2 \\
\hline & $1 / 3$ & ME & $\mathrm{ME}$ & $\mathrm{ME}$ & 44 & 121 & 20 \\
\hline & 1 & $\mathrm{ME}$ & $\mathrm{ME}$ & $\mathrm{ME}$ & 109 & $\mathrm{ME}$ & 32 \\
\hline & 3 & $\mathrm{ME}$ & $\mathrm{ME}$ & $\mathrm{ME}$ & 253 & $\mathrm{ME}$ & 42 \\
\hline \multirow{2}{*}{$\begin{array}{l}\text { Policy Rule } \\
\text { Specification }\end{array}$} & & \multicolumn{3}{|c|}{ Optimized for MSR } & \multicolumn{3}{|c|}{ Optimized for TMCM } \\
\hline & $\lambda$ & FM & FRB & TMCM & FM & FRB & MSR \\
\hline \multirow{4}{*}{ FB4 } & 0 & 20 & 5 & 4 & 15 & -3 & 13 \\
\hline & $1 / 3$ & 27 & -0 & 5 & 22 & 17 & 20 \\
\hline & 1 & 29 & -4 & 3 & 42 & 4 & 19 \\
\hline & 3 & 38 & -4 & 0 & 49 & -1 & 4 \\
\hline \multirow{4}{*}{ FB1 } & 0 & 23 & 13 & 6 & 39 & -6 & 22 \\
\hline & $1 / 3$ & 34 & 4 & 2 & 9 & 6 & 11 \\
\hline & 1 & 37 & 3 & 2 & 18 & 6 & 16 \\
\hline & 3 & 46 & -1 & 0 & 72 & 6 & 21 \\
\hline \multirow{4}{*}{ FB4XG } & 0 & 28 & 6 & 4 & 47 & -6 & 14 \\
\hline & $1 / 3$ & 11 & $\mathrm{ME}$ & 83 & 48 & 179 & 204 \\
\hline & 1 & 35 & $\mathrm{ME}$ & 176 & 89 & 493 & 331 \\
\hline & 3 & 84 & $\mathrm{ME}$ & 323 & 198 & $\mathrm{ME}$ & $\mathrm{ME}$ \\
\hline
\end{tabular}

Note: For each specification of the policy rule (see notes to Table 3 ) and each value of the preference parameter $\lambda$, the optimized rule is taken from the specified "rule-generating" model, and then this rule is evaluated in each alternative "true economy" model using model-consistent forecasts. The notation "ME" indicates that the rule yields multiple equilibria; otherwise, the entry indicates the percent deviation of the loss function from the outcome-based policy frontier of the true economy model $(\% \Delta \mathcal{L})$. 
indistinguishable from unrestricted FB4 rules), these rules almost uniformly generate very high losses or indeterminacy (which we interpret as an arbitrarily high value of the loss function). For example, the FB4XG rules optimized for TMCM with $\lambda=1 / 3$ yield losses exceeding 150 percent in FRB and MSR, while all of the FB4XG rules optimized for the FM model with $\lambda>0$ generate multiple equilibria in all three of the other models. These results follow directly from the specific characteristics of optimized FB4XG rules: when $\lambda>0$, these rules involve relatively little interest rate smoothing, a highly aggressive response to a relatively long-horizon inflation forecast, and, by assumption, no explicit response to the output gap. As we pointed out in Section 3, these characteristics are exactly the ones that tend to result in indeterminacy, especially in models like MSR and TMCM that have a relatively low degree of intrinsic inertia.

\subsection{Robustness with Model-Inconsistent Forecasts}

Now we investigate the consequences of using model-inconsistent forecasts; that is, we assume that the policy rule is optimized using a misspecified model, and that the rule is then implemented using forecasts generated by the same misspecified model. After determining the optimized policy rule for a particular model, we obtain the reduced-form representations of the relevant inflation and output gap forecasts in terms of the state variables of the model, and we add these reduced-form forecast equations to the model of the true economy. The policy rule is expressed in terms of the misspecified forecasts, which are obtained by evaluating these reduced-form forecast equations using the data generated by the true economy model. Thus, this procedure presumes that the state variables from the policymaker's model also appear in the true economy model; that is, the misspecified model is nested within the true economy model. For this reason, we consider cases in which the FM model constitutes the policymaker's model while one of the other three models represents the true economy, and we also consider cases in which the MSR model constitutes the policymaker's model while either FRB or TMCM represents the true economy.

The results of this exercise are reported in the upper part of Table 5. As in the preceding subsection, we evaluate the relative performance $(\% \Delta \mathcal{L})$ of each policy rule compared with the optimized outcome-based rule that generates the same level of interest rate volatility in the true economy model. Comparing these results regarding the robustness of forecast-based rules with the outcomes presented previously in Table 4 (repeated in the lower part of Table 5), we find that in most cases performance deteriorates when the model-inconsistent forecast is used, especially in the case of rules optimized in the MSR model and evaluated in the FRB or TMCM models. However, there are exceptions to this pattern, for example in the case of rules optimized in the FM model and evaluated in the MSR model. Overall the magnitude of the difference in loss compared to the optimized OB rule is not very large and never exceeds 50 percent. 
Table 5: Implications of Model-Inconsistent Forecasts

\begin{tabular}{|c|c|c|c|c|c|c|}
\hline & \multirow[b]{2}{*}{$\lambda$} & \multicolumn{3}{|c|}{ Optimized for FM } & \multicolumn{2}{|c|}{ Optimized for MSR } \\
\hline & & FRB & MSR & TMCM & FRB & TMCM \\
\hline \multirow{4}{*}{$\begin{array}{l}\text { Model-inconsistent } \\
\text { forecasts }\end{array}$} & 0 & 14 & 39 & 5 & 4 & - \\
\hline & $1 / 3$ & 6 & 14 & 9 & 3 & 14 \\
\hline & 1 & 14 & 19 & 15 & 11 & 32 \\
\hline & 3 & 25 & 25 & 22 & 21 & 45 \\
\hline \multirow{4}{*}{$\begin{array}{l}\text { Model-consistent } \\
\text { forecasts }\end{array}$} & 0 & 7 & 40 & -0 & 5 & 4 \\
\hline & $1 / 3$ & 5 & 27 & 12 & -0 & 5 \\
\hline & 1 & 9 & 41 & 11 & -4 & 3 \\
\hline & 3 & 6 & 57 & 9 & -4 & 0 \\
\hline
\end{tabular}

Note: For each value of the preference parameter $\lambda$, the optimized FB4 rule is taken from the specified "rule-generating" model (either FM or MSR), and then this rule is evaluated in each alternative "true economy" model. In the upper panel, the rule is implemented using forecasts obtained from the rule-generating model; in the lower panel, the rule is implemented using forecasts obtained from the true economy model (as in Table 4). Each entry indicates the percent deviation of the loss function from the outcome-based policy frontier of the true economy model $(\% \Delta \mathcal{L})$.

\subsection{Rules with Fixed Forecast Horizons}

We have seen that optimized FB4 rules involve relatively short forecast horizons (0-4 quarters) and are remarkably robust to model uncertainty. Now we consider the degree of robustness of rules with longer forecast horizons. In particular, we analyze the performance of FB4 rules in which the inflation forecast horizon is fixed at either one or two years (that is, $\theta=4$ or 8), and that respond either to the current output gap or to its one-year-ahead forecast (that is, $\kappa=0$ or 4 ).

For a given value of $\lambda$ and a given combination of the output and inflation forecast horizons, we determine the optimal policy rule parameters $(\rho, \alpha$, and $\beta)$ for each of the four macroeconometric models, using the methods described in Section 4. Then we evaluate the performance of the rule in each of the other models, following the methodology described above. For brevity, we focus on the robustness of these rules in the optimizing AD-AS model using model-consistent forecasts. Table 6 indicates the relative loss of each rule $(\% \Delta \mathcal{L})$ compared with the OB policy frontier. ${ }^{27}$

Forecast-based rules that respond to a four-quarter inflation forecast and the current output gap are generally quite robust to model uncertainty, especially when the policymaker places nonnegligible weight on stabilizing output as well as inflation $(\lambda>0)$. In contrast, optimized rules with

\footnotetext{
${ }^{27}$ The coefficients of each optimized fixed-horizon rule are reported in Appendix Table A3. The robustness of these rules in the four macroeconometric models is reported in Tables A4 and A5 for model-consistent and modelinconsistent forecasts, respectively. In the MSR and TMCM models, the optimized rules obtained for $\theta=\kappa=4$ lie right on the edge of the indeterminacy region. For the set of rules that yield a unique stationary equilibrium, the optimum is obtained by rules that generate less interest rate variability than rule A; this is the only case in our analysis for which the interest rate variability constraint is not binding.
} 
Table 6: Robustness of Fixed-Horizon FB4 Rules in the Optimizing AD-AS Model

\begin{tabular}{|c|c|c|c|c|c|c|}
\hline \multicolumn{2}{|c|}{$\begin{array}{l}\text { Forecast } \\
\text { Horizons }\end{array}$} & \multirow[b]{2}{*}{$\lambda$} & \multicolumn{4}{|c|}{ Rule-Generating Model } \\
\hline$\theta$ & $\kappa$ & & FM & FRB & MSR & TMCM \\
\hline \multirow[t]{4}{*}{4} & 0 & 0 & 210 & 191 & $\mathrm{ME}$ & 216 \\
\hline & & $1 / 3$ & 26 & 13 & 10 & 12 \\
\hline & & 1 & 34 & 10 & 8 & 13 \\
\hline & & 3 & 38 & 11 & 10 & 16 \\
\hline \multirow[t]{4}{*}{8} & 0 & 0 & $\mathrm{ME}$ & $\mathrm{ME}$ & $\mathrm{ME}$ & $\mathrm{ME}$ \\
\hline & & $1 / 3$ & 10 & 12 & 9 & $\mathrm{ME}$ \\
\hline & & 1 & 31 & 9 & 7 & 11 \\
\hline & & 3 & 25 & 11 & 9 & 14 \\
\hline \multirow[t]{4}{*}{4} & 4 & 0 & 194 & 204 & $\mathrm{ME}$ & 221 \\
\hline & & $1 / 3$ & ME & $\mathrm{ME}$ & ME & $\mathrm{ME}$ \\
\hline & & 1 & ME & ME & $\mathrm{ME}$ & $\mathrm{ME}$ \\
\hline & & 3 & $\mathrm{ME}$ & $\mathrm{ME}$ & $\mathrm{ME}$ & $\mathrm{ME}$ \\
\hline
\end{tabular}

Note: For each value of the preference parameter $\lambda$ and each choice of the inflation forecast horizon $\theta$ and output gap forecast horizon $\kappa$, the coefficients of the rule are optimized using the specified "rule-generating" model, and then this rule is evaluated in the optimizing AD-AS model using model-consistent forecasts. Each entry indicates the percent deviation of the loss function from the outcome-based policy frontier of the optimizing AD-AS model $(\% \Delta \mathcal{L})$; the notation "ME" indicates that the rule yields multiple equilibria.

an eight-quarter inflation forecast horizon or a four-quarter output gap forecast are markedly less robust, including a much greater incidence of multiple equilibria. This lack of robustness primarily reflects the substantial differences in output and inflation dynamics across the various models.

\section{Identifying a Robust Benchmark Rule}

Our previous analysis has highlighted the general characteristics of forecast-based rules that are robust to model uncertainty; in this section, we proceed to identify a specific rule that can serve as a robust benchmark for monetary policy. None of the rules taken from the literature (listed in Table 1) is satisfactory for this purpose: most of those rules generate indeterminacy in one or more of the five models (see Table 2), while the remaining rules perform quite poorly relative to the outcome-based policy frontier (see Appendix Table A6). Therefore, for each value of the preference parameter $\lambda$, we now determine the policy rule that minimizes the average loss function across all five models, subject to an upper bound on the level of interest rate volatility in each model.

In particular, we assume that the policymaker's loss function $\overline{\mathcal{L}}$ is given by:

$$
\overline{\mathcal{L}}=\frac{1}{5}\left(\mathcal{L}_{O P T}+\mathcal{L}_{F M}+\mathcal{L}_{F R B}+\mathcal{L}_{M S R}+\mathcal{L}_{T M C M}\right)
$$


Table 7: Minimizing the Average Loss Across All Five Models

\begin{tabular}{|c|c|c|c|c|c|c|c|c|}
\hline \multirow[b]{2}{*}{$\lambda$} & \multicolumn{3}{|c|}{ Optimal Parameters } & \multicolumn{5}{|c|}{ Stabilization Performance $(\% \Delta \mathcal{L})$} \\
\hline & $\rho$ & $\alpha$ & $\beta$ & Opt. AD-AS & FM & FRB & MSR & TMCM \\
\hline 0 & 1.02 & 0.66 & 0.08 & 139 & 1 & 0 & 42 & 1 \\
\hline $1 / 3$ & 0.97 & 0.45 & 0.41 & 19 & 9 & 9 & 15 & 1 \\
\hline 1 & 0.92 & 0.30 & 0.53 & 23 & 7 & 14 & 15 & 1 \\
\hline 3 & 0.89 & 0.19 & 0.60 & 29 & 4 & 22 & 18 & 4 \\
\hline
\end{tabular}

Note: For each value of the preference parameter $\lambda$, the corresponding row of this table indicates the parameters and stabilization performance of the optimal FB4 rule (with fixed forecast horizons $\theta=4$ and $\kappa=0$ ) that minimizes the average loss function $\overline{\mathcal{L}}$ across all five models, subject to the constraint that in every model the unconditional standard deviation of $\Delta i_{t}$ cannot exceed the value generated by the estimated rule A. The stabilization performance in each model is measured by the percent deviation of the loss function from the OB policy frontier of that model $(\% \Delta \mathcal{L})$.

where $\mathcal{L}_{i}$ is the value of the loss function (7) obtained by evaluating a particular policy rule in model $i$. Thus, from a Bayesian perspective, $\overline{\mathcal{L}}$ corresponds to the expected loss function when the policymaker has flat prior beliefs regarding which of these five models is the correct representation of the economy.

In light of our earlier results, we focus exclusively on the class of rules that respond to the oneyear-ahead forecast of the smoothed inflation rate and to the current output gap (that is, FB4 rules with $\theta=4$ and $\kappa=0$ ). Thus, for a given value of $\lambda$, we find the values of the policy parameters $(\alpha, \beta$, and $\rho)$ that minimize $\overline{\mathcal{L}}$, subject to the constraint that in every model the unconditional standard deviation of $\Delta i_{t}$ cannot exceed the value generated by the estimated rule $\mathrm{A}$. The results of this optimization are reported in Table 7.

For a policymaker who is concerned solely with stabilizing inflation $(\lambda=0)$, the optimized rule works very well in several of the macroeconometric models but performs poorly in the optimizing AD-AS model. In this case, it is apparent that no single rule is near-optimal in all five models. Thus, the rule given in Table 7 is the optimal choice for a policymaker with flat priors concerning the relative accuracy of the five models, and would also be nearly optimal for any policymaker who has reasonable confidence in the four macroeconometric models and is relatively skeptical about the accuracy of the optimizing AD-AS model. In contrast, this rule would be far from optimal for a policymaker who discounts the relevance of the four macroeconometric models and who has strong prior beliefs that the optimizing AD-AS model is the best representation of the true economy.

In contrast, for a policymaker who is concerned with stabilizing both inflation and the output gap $(\lambda>0)$, we find that each optimized rule performs remarkably well in all five models, especially considering the dramatically different dynamic properties of these models. For example, when $\lambda=1 / 3$, Table 7 indicates that the loss function value generated by the optimized rule never 
Table 8: Stabilization Performance of the Benchmark Forecast-Based Rule

\begin{tabular}{cccccc}
$\lambda$ & Opt. AD-AS & FM & FRB & MSR & TMCM \\
\hline $1 / 3$ & 16 & 12 & 7 & 16 & 1 \\
1 & 19 & 7 & 20 & 6 & 0 \\
3 & 22 & 23 & 48 & 12 & 0 \\
\hline \hline
\end{tabular}

Note: For each value of the preference parameter $\lambda$, the corresponding row of this table indicates the percent deviation of the loss function obtained by the benchmark forecast-based rule (given in equation $(9)$ from the OB policy frontier of each model $(\% \Delta \mathcal{L})$.

deviates more than 20 percent from the outcome-based policy frontier of each model. Evidently, choosing the policy parameters to minimize the average loss function across the five models does not incur large stabilization costs relative to fine-tuning these parameters to a given model. Thus, the same rule would be nearly optimal even for a policymaker with very different (non-flat) prior beliefs about the accuracy of the five models.

It is also striking that the policy rule parameters in Table 7 are quite similar for all three nonzero values of $\lambda$. This suggests the possibility of identifying a benchmark rule that performs well for a fairly wide range of policy preferences as well as for a wide range of prior beliefs about the dynamic properties of the economy.

Therefore, we now consider the following simple forecast-based policy rule, which has parameter values nearly identical to those of the optimized rule for $\lambda=1 / 3$ :

$$
i_{t}=1.0 i_{t-1}+0.4\left(\pi_{t+4}-\pi^{*}\right)+0.4 y_{t} .
$$

Table 8 indicates the stabilization performance of this rule for each value of $\lambda>0$. As one would expect, the rule performs very well in all five models when $\lambda=1 / 3$. This rule also performs remarkably well when $\lambda=1$; as in the previous case, the loss function never deviates more than 20 percent from the outcome-based policy frontier. The rule provides reasonably robust performance even for $\lambda=3$, although the maximum value of $\% \Delta \mathcal{L}$ does reach nearly 50 percent in this case. Based on these results, we conclude that this rule can serve as a robust benchmark for monetary policy, at least for policymakers who place non-trivial weight on stabilizing the output gap as well as the inflation rate. 


\section{Conclusion}

In this paper, we have analyzed the performance and robustness of forecast-based monetary policy rules using five models that reflect divergent views about the dynamic properties of the U.S. economy. Our analysis yields the following conclusions:

- While forecast-based rules can serve as a useful framework for monetary policy, this class of rules does not provide substantial gains in stabilization performance compared with simple outcome-based rules.

- Determinacy is an important consideration in selecting a robust forecast-based rule. For example, a number of policy rules proposed in the literature generate multiple equilibrium in several of the macroeconomic models considered here.

- Robust policy rules respond to a short-horizon forecast (not exceeding one year) of a smoothed measure of inflation, incorporate a substantial response to the current output gap, and involve a relatively high degree of policy inertia.

- We have identified a specific forecast-based rule that can serve as a robust benchmark for monetary policy; this rule performs remarkably well in all five models for a wide range of policy preferences.

Our analysis also suggests several fruitful areas for future research. First, while this paper has focused exclusively on models with rational expectations and short-run nominal inertia, our methodology can be applied to an even broader set of models that incorporate alternative assumptions about expectations formation and about the transmission mechanism of monetary policy; this methodology can also be used in identifying robust policy rules for other economies with different structural characteristics (e.g., small open economies and emerging market economies). Second, our analysis has focused on instrument rules in which the short-term nominal interest rate responds directly to the inflation forecast, and has not considered the performance of targeting rules that explicitly minimize the weighted average of the variances of inflation and the output gap at a particular forecast horizon (cf. Svensson (1997), Svensson and Woodford (1999)); in future work, it will be useful to investigate the extent to which such rules are robust to model uncertainty. Finally, we have proceeded under the assumption that the parameters of each competing model are known exactly and that the data series are measured precisely; additional research will be required to identify rules that are robust to parameter uncertainty and data uncertainty as well as to model uncertainty. 


\section{Appendix}

\section{A.1 Forecast-Based Policy Rules From the Literature}

This appendix provides additional information regarding the policy rules given in Table 1 .

The coefficients of rules B and $\mathrm{C}$ were not optimized to a particular model; rather, these rules were fitted to U.S. data from the past two decades. In particular, rule B is taken from Clarida et al. (1999a), who estimated this equation by two-stage least squares using quarterly U.S. data over the period 1982:4-1996:4. The specification of rule B is defined on page 4 and page 8 by equations 2.1 and 2.3; the parameter estimates are taken from table 3 of the same paper. Rule $\mathrm{C}$ is taken from Orphanides (1998), who estimated this rule using real-time data on Federal Reserve staff forecasts of U.S. output gaps and GDP price inflation for the period 1987-1992. ${ }^{28}$ Rules B and C both suggest that U.S. short-term nominal interest rates during the bulk of the Volker-Greenspan era can be described reasonably well in terms of systematic responses to a one-year-ahead inflation forecast, the lagged funds rate, and either the current output gap or its one-year-ahead forecast.

Rule D is taken from de Brouwer and Ellis (1998), who found this rule to be near-efficient in a small model of the Australian economy. The specification of the rule is discussed on page 12 (equation $2 \mathrm{~b}$ ), while the good performance for the above choice of parameters is noted on page 16 . This rule involves one-year-ahead forecasts of both the output gap and inflation rate (as in rule C), but does not involve the lagged funds rate.

Rule E is taken from Batini and Nelson (2001), who found that, among the class of rules that only respond to expected inflation and the lagged short-term interest rate, this rule minimizes the sum of inflation and output variability in a small rational expectations model of the U.K. economy.

Rule $\mathrm{F}$ is taken from Isard et al. (1999), who found this rule to perform well in a small moderately-nonlinear model of the U.S. economy with a time-varying NAIRU (Table 8, page 41).

Rules $\mathrm{G}$ and $\mathrm{H}$ are taken from Rudebusch and Svensson (1999). The generic form of the rule is discussed on page 222 of that paper; the two parameterizations are taken from table 5.4. on page 228. As noted in the text, these two rules involve the one-quarter annualized inflation rate rather than the four-quarter average inflation rate. Conditional on the inflation forecast horizon (either 8 or 12 quarters), the coefficients of each rule were optimized using a small U.S. macroeconometric model with adaptive expectations. Both rules perform nearly as well as the fully-optimal policy rule that involves the entire set of state variables of the model. The response coefficients are computed by minimizing a loss function which assigns a relatively high weight to inflation variability. The percentage difference compared to the fully optimal policy under this loss function is less than 2 percent.

Rule I is taken from Batini and Nelson (2001), who found that, among the class of rules that only respond to expected inflation and the lagged short-term interest rate, this rule minimizes the sum of inflation and output variability in a small adaptive expectations model of the U.K. economy.

\footnotetext{
${ }^{28}$ The parameter estimates are taken from the last column of table 8 in Orphanides (1998b). The table also provides a definition of the rule. Orphanides considered forecast horizons of zero to four quarters for both the output gap and inflation, and found that specifications such as rule C involving one-year-ahead forecasts exhibited the most sensible point estimates and the best goodness-of-fit.
} 
(It should be noted that the same authors found rule $\mathrm{E}$ to be optimal under rational expectations).

Rule $\mathrm{J}$ is taken from Amano et al. (1999). In this case short-term nominal interest rates are adjusted so that the spread between short and long rates moves in response to a two-yearahead forecast of the four-quarter inflation rate. According to the authors, this rule provides a good approximation to the reference interest rate reaction function used in the Bank of Canada's Quarterly Projection Model (page 14); the rule is defined by equation 5 on page 13 of that paper.

Finally, rule $\mathrm{K}$ is taken from Batini and Haldane (1999), who analyzed various types of policy rules in a small forward-looking open-economy model of the Bank of England calibrated to match U.K. data. This rule is quite similar to rule G, except that the monetary policy instrument is defined in terms of the ex ante real interest rate, $i_{t}-E_{t} \pi_{t+1}$. The general form of the rule is given by equation 1 on page 158 of their paper, while the coefficients of the reference rule are reported on page 173 .

\section{A.2 The Five Macroeconomic Models}

This appendix provides further details regarding the five macroeconomic models utilized in this paper.

The small stylized model is taken from Woodford (2000a), except that we express nominal interest rates and inflation at annual rates, and our aggregate supply relation includes an exogenous disturbance. (Our model is also very similar to those used in Bernanke and Woodford (1997), Rotemberg and Woodford (1997), and Rotemberg and Woodford (1999), except that those models incorporate decision lags for spending and price-setting.) In particular, $\pi$ indicates the deviation of the one-quarter inflation rate from steady state, $y$ indicates the logarithmic deviation of output from its flexible-price level, and $r^{*}{ }_{t}$ indicates the deviation of the Wicksellian (i.e., flexible-price) real interest rate from steady state. Equation (3) can be obtained as a log-linear approximation to the first-order condition of optimizing firms with either Calvo-style staggered price contracts (Yun (1996)) or convex costs of price adjustment (Rotemberg (1982)); the exogenous disturbance $\epsilon_{t}$ may be viewed as representing transitory changes in monopoly power or tax distortions. (Shifts in the price markup arise endogenously when both wages and prices are determined by staggered nominal contracts; cf. Erceg, Henderson and Levin (2000).) Equation (4) can be obtained as a log-linear approximation of the representative household's first-order equation in a model in which consumption, leisure, and real money balances are each additively separable in the utility function, and total consumption demand is equal to aggregate output.

The basic characteristics of the four structural macroeconometric models are summarized in Table A1. The method of estimating the structural parameters also varies across the four models: full-information maximum likelihood estimation was used in estimating the parameters of the FM model, while the parameters of the other three models were estimated using a combination of ordinary least squares, two-stage least squares and the generalized method of moments. In the remainder of this appendix, we highlight further details regarding the specification of aggregate demand, aggregate supply, and the foreign sector of each model.

Aggregate Demand. The FM model represents aggregate spending by a single reduced-form 
Table A1: Basic Characteristics of Four Macroeconometric Models

\begin{tabular}{lcccc}
\hline & FM & FRB & MSR & TMCM \\
& & & & \\
\hline IS Components & 1 & 17 & 5 & 10 \\
Price Variables & 2 & 7 & 2 & 5 \\
Labor Variables & 0 & 4 & 0 & 0 \\
Asset Prices & 1 & 7 & 2 & 2 \\
Foreign Variables & 0 & $2^{2}$ & 0 & 95 \\
\hline Wage and Price & Staggered & Generalized & Staggered & Staggered \\
Dynamics & real wage & adjustment & real wage & nominal \\
& contracts & costs & contracts & contracts \\
\hline Duration of Bond & 10 years & 5/10/30 years ${ }^{3}$ & 2 years & 2 years \\
Permanent Income & N/A & $7 \%$ & $10 \%$ & $10 \%$ \\
Discount Rate & \multicolumn{5}{c}{ per quarter } & per quarter & per quarter \\
Estimation Period & 1966-94 ${ }^{1}$ & $1966-95$ & $1980-96$ & $1971-86$ \\
\hline \hline
\end{tabular}

Notes: 1. FM estimated over 1966:1-1994:4; residuals are computed from 1982:4-1994:1. 2. The full FRB model contains over 400 foreign variables; in the version of the FRB model used in this paper, these have been replaced by 2 equations for foreign output and prices. 3. The FRB model includes bonds with durations of 5, 10 and 30 years, as well as equity prices. The 5-year bond is used in computing the cost of capital for business equipment and consumer purchases of durables.

equation corresponding to an IS curve. The current output gap depends on its lagged values over the past two quarters and the lagged value of the long-term real interest rate, which is defined as a weighted average of ex ante short-term real interest rates with maturity equivalent to a 30year coupon bond. The parameter estimates are taken from Fuhrer (1997a). The FM model does not explicitly include trade variables or exchange rates; instead, net exports (and the relationship between real interest and real exchange rates) are implicitly incorporated in the IS curve equation. The MSR model disaggregates real spending into five components: private consumption, fixed investment, inventory investment, net exports, and government purchases. The aggregate demand components exhibit partial adjustment to their respective equilibrium levels, measured as shares of potential GDP. Equilibrium consumption is a function of permanent income (discounted 10

The TMCM model disaggregates IS components further; for example, spending on fixed investment is separated into three components: equipment, nonresidential structures, and residential construction. The specification of these equations is very similar to that of the more aggregated equations in the MSR model. In TMCM, imports follow partial adjustment to an equilibrium level that depends on U.S. income and the relative price of imports, while exports display partial ad- 
justment to an equilibrium level that depends on foreign output and the relative price of exports. Uncovered interest rate parity determines each bilateral exchange rate (up to a time-varying risk premium); e.g., the expected one-period-ahead percent change in the DM/USDollar exchange rate equals the current difference between U.S. and German short-term interest rates.

The FRB model features about the same level of aggregation as TMCM for private spending but divides government spending into six components, each of which follows a simple reduced-form equation that includes a counter-cyclical term. The specification of most non-trade private spending equations follows the generalized adjustment cost model due to Tinsley (1993).

Each component has a specific flow or stock equilibrium condition; for example, equilibrium aggregate consumption is proportional to wealth. Households and businesses adjust their spending in each category according to the solution of a quadratic adjustment cost problem. The resulting spending decision rules are specified as forward-looking error correction equations: the current growth of each spending variable depends on up to three of its own lagged values and on expected future growth in equilibrium spending, and responds negatively to the lagged percent deviation between actual and equilibrium spending levels. Exports and non-oil imports are specified as error-correction processes with long-run income and price elasticities set equal to unity. Uncovered interest rate parity determines the multilateral exchange rate, subject to a sovereign risk premium that moves with the U.S. net external asset position.

Aggregate Supply. In FM, MSR, and TMCM, the aggregate wage rate is determined by overlapping wage contracts. In particular, the aggregate wage is defined to be the weighted average of current and three lagged values of the contract wage rate. TMCM follows the specification in Taylor (1980), where the current nominal contract wage is determined as a weighted average of expected nominal contract wages, adjusted for the expected state of the economy over the life of the contract. FM and MSR use the overlapping real contract wage specification proposed by Buiter and Jewitt (1981) and implemented by Fuhrer and Moore (1995), in which the real contract wage, that is the contract wage deflated by the aggregate wage, is determined as a weighted average of expected real contract wages, adjusted for the expected average output gap over the life of the contract.

In FM and MSR, the aggregate price level is a constant markup over the aggregate wage rate. In contrast, the output price in TMCM follows a backward-looking error-correction specification: current output price inflation depends positively on its own lagged value, on current wage inflation, and on lagged import price inflation, and responds negatively (with a coefficient of -0.2) to the lagged percent deviation of the actual price level from equilibrium. Import prices error-correct slowly to an equilibrium level equal to a constant markup over a weighted average of foreign prices converted to dollars. This partial adjustment of import and output prices imparts somewhat more persistence to output price inflation than would result from staggered nominal wages alone.

The FRB model explicitly models potential output as a function of the labor force, crude energy use, and a composite capital stock, using a three-factor Cobb-Douglas production technology. The equilibrium output price is a markup over a weighted average of the productivity-adjusted wage rate and the domestic energy price. The specification of wage and price dynamics follows the 
generalized adjustment cost framework used in the FRB IS block. Wage inflation depends on lagged wage inflation over the previous three quarters, as well as expected future growth in prices and productivity, and a weighted average of expected future unemployment rates. Price inflation depends on its own lagged values over the past two quarters, as well as expected future changes in equilibrium prices and expected future unemployment rates. In addition, both wages and prices error-correct to their respective equilibrium levels. As in the other models, a vertical long-run Phillips curve is imposed in estimation.

Unlike the other three models, the FRB model contains a detailed accounting of various categories of income, taxes, and stocks, an explicit treatment of labor markets, and endogenous determination of potential output. Long-run equilibrium in the FRB model is of the stock-flow type; the income tax rate and real exchange rate risk premium adjust over time to bring government and foreign debt-to-GDP ratios back to specified (constant) levels.

The Foreign Sector. Neither FM nor MSR explicitly include foreign variables; in contrast, both TMCM and the full FRB staff model include detailed treatments of foreign variables. TMCM features estimated equations for demand components and wages and prices for the other G-7 countries at about the level of aggregation of the U.S. sector. The full FRB staff model includes a total of 12 sectors (countries or regions) which encompass the entire global economy. Because of the size of the model, the cost of solving and computing the moments of the full FRB model is prohibitive. Previous investigations using TMCM suggest that the characteristics of optimal U.S. monetary policies are not greatly affected by the precise specification of the foreign sector (see Levin et al. (1999)). Based on these results and the benefits of reduced computational cost, we replaced the full set of equations describing foreign countries in the FRB staff model with two simple reduced form equations for foreign output and prices.

\section{A.3 Methodology}

Here we describe the methods used to solve each model and obtain its unconditional moments for a specific interest rate rule. Then we specify the objective function and constraints faced by the monetary policymaker, and describe how to obtain the optimal response parameters for a given type of rule.

Analyzing a Specific Rule. Our methodology permits the analysis of a wide variety of rules in which the federal funds rate may depend on its own lagged values as well as the current, lagged, and expected future values of other model variables. In general, the interest rate rule can be expressed as follows:

$$
i_{t}=\sum_{j=1}^{l} H_{j}^{1} i_{t-j}+\sum_{j=1}^{m} H_{j}^{2} E_{t} z_{t+j}+\sum_{j=1}^{n} H_{j}^{3} z_{t-j}
$$

where $i_{t}$ is the federal funds rate and the vector $z$ is a set of model variables that enter the interest rate reaction function. The lagged funds rate coefficients are given by $H_{j}^{1}(j=1$ to $l)$, while the coefficients on other model variables are given by the vectors $H_{j}^{2}(j=1$ to $m)$ and $H_{j}^{3}(j=0$ to $n)$. Henceforth we will refer to the combined set of coefficients by the vector $H=\left\{H^{1}, H^{2}, H^{3}\right\}$. After 
discussing how to compute the moments of each model for a specific value of $H$, we will consider the problem of determining the optimal value of $H$ for a given choice of the elements of $z$ and the lead and lag orders $l, m$, and $n$.

As in Fuhrer (1997a), we analyze the performance of a specified policy rule in each model by computing the reduced form representation of the saddle point solution and then evaluating an analytic expression for the unconditional second moments of the model variables. For linear models, this approach yields accurate results far more efficiently than simulation-based methods. To take advantage of these methods, we have constructed a linearized version of TMCM and a log-linear version of the FRB model; however, these approximations have negligible effects on the relevant dynamic properties of the two models.

Thus, each of the four models can be written in the following form:

$$
\sum_{j=1}^{M} A_{j} E_{t} x_{t+j}+\sum_{j=1}^{N} A_{j} x_{t-j}+C e_{t}=0
$$

where $\mathrm{x}$ is the vector of all model variables, and e is a vector of serially uncorrelated disturbances with mean zero and finite covariance matrix $\Omega$. The interest rate reaction function comprises a single row of equation (11), while the remaining rows contain the structural equations of the model. Thus, the parameters of the interest rate rule are contained in one row of the coefficient matrices $A_{j}(j=1$ to $M)$ and $B_{j}(j=0$ to $N)$, while this row of $C$ is identically equal to zero.

We compute the unique stationary rational expectations solution to equation (11) using the Anderson and Moore (1985) implementation of the Blanchard and Kahn (1980) method, modified to take advantage of sparse matrix functions. The reduced form of this solution can be expressed as follows:

$$
x_{t}=\sum_{j=1}^{N} D_{j}(H) x_{t-j}+F(H) e_{t}
$$

where the reduced-form coefficient matrices $D_{j}(j=1$ to $N)$ and $F$ depend on the monetary policy parameters $H$ as well as the structural parameters of the model. By defining the vector $\tilde{x_{t}}=\left(x_{t-1}, \ldots ., x_{t-N}\right)$, we can express this solution in companion form:

$$
\tilde{x}_{t}=P(H) \tilde{x}_{t-1}+Q(H) e_{t}
$$

Then the unconditional contemporaneous covariance matrix for $\tilde{x}_{t}$, denoted by $V_{0}$, is given by:

$$
V_{0}=\sum_{j=0}^{\infty} P^{j} Q \Omega Q^{\prime} P^{\prime j}
$$

Using the implicit expression $V_{0}=P V_{0} P+Q \Omega Q$, we compute $V_{0}$ iteratively using the doubling algorithm described in Hansen and Sargent (1997), modified to take advantage of sparse matrix functions. Given $V_{o}$, the autocovariance matrices of $\tilde{x}_{t}$ are readily computed using the relationship $V_{j}=P^{j} V_{0}$.

The Optimization Problem. For specified values of $\lambda$ and $\bar{\sigma}_{\Delta i}$, and for a given functional form of the policy rule, we determine the parameter values of this rule that minimize the loss 
function in equation (7) subject to the constraint that the unconditional standard deviation of $\Delta i_{t}$ cannot exceed $\bar{\sigma}_{\Delta i}$. For a given set of rule parameters, we use the methods described above to obtain the reduced-form solution matrices $G$ and $H$, compute the unconditional moments, and calculate the value of the objective function. To determine the optimal parameters of the rule, we use the Matlab CONSTR routine, which iteratively updates the parameter vector in order to minimize the loss function subject to the fnds rate volatility constraint and the restriction that the optimal rule must yield a unique rational expectations equilibrium.

Thus, to solve this optimization problem, it is necessary to compute hundreds or even thousands of rational expectations solutions at alternative values of the policy rule parameters. Given our objective of performing a systematic analysis of policy frontiers for a range of different functional forms of the interest rate rule, it is essential to make use of the highly efficient solution algorithms outlined above. On a Sun Ultra Enterprise 3000 computer about as fast as an Intel Pentium II $300 \mathrm{Mhz}$ computer only a few CPU seconds are needed to solve and compute the moments of a small-scale model like FM or MSR, while solving a large-scale macroeconometric model like TMCM or the FRB model requires about five CPU minutes. 


\section{A.4 Coefficients of Optimized Rules}

Table A2 reports the optimized values of $\rho, \alpha$, and $\beta$ for each of the forecast-based rules considered in Section 4; the optimized values of the inflation forecast horizon $\theta$ and the output gap forecast horizon $\kappa$ of each rule are indicated in Table 3. Table A3 reports the optimized values of $\rho$, $\alpha$, and $\beta$ for the rules with fixed forecast horizons considered at the end of Section 5.

Table A2: Coefficients of Optimized Forecast-Based Rules

\begin{tabular}{|c|c|c|c|c|c|c|c|c|c|c|}
\hline \multirow[t]{2}{*}{ Model } & \multirow[t]{2}{*}{$\lambda$} & \multicolumn{3}{|c|}{ FB4 Rules } & \multicolumn{3}{|c|}{ FB1 Rules } & \multicolumn{3}{|c|}{ FB4XG Rules } \\
\hline & & $\rho$ & $\alpha$ & $\beta$ & $\rho$ & $\alpha$ & $\beta$ & $\rho$ & $\alpha$ & $\beta$ \\
\hline \multirow{4}{*}{$\begin{array}{l}\text { Opt. } \\
\text { AD-AS }\end{array}$} & 0 & .78 & 16.55 & -.64 & 1.78 & 12.37 & 0.02 & 1.57 & 51.46 & - \\
\hline & $1 / 3$ & 1.57 & 7.27 & 6.12 & 1.50 & 2.41 & 5.94 & 0.42 & 8.80 & - \\
\hline & 1 & 1.55 & 3.04 & 6.23 & 1.52 & 1.18 & 6.15 & 0.42 & 8.90 & - \\
\hline & 3 & 1.55 & 1.49 & 6.26 & 1.53 & 0.75 & 6.23 & 0.47 & 8.34 & - \\
\hline \multirow{5}{*}{ FM } & 0 & .96 & .51 & .10 & .97 & 0.45 & .10 & 1.21 & 2.55 & - \\
\hline & $1 / 3$ & .97 & .86 & .68 & 1.27 & 1.95 & 2.07 & 1.28 & 20.29 & - \\
\hline & 1 & 1.00 & .67 & .98 & 1.35 & 2.11 & 3.66 & .77 & 4.60 & - \\
\hline & 3 & 1.02 & .43 & 1.12 & 1.60 & 1.97 & 5.66 & .62 & 3.47 & - \\
\hline & 0 & 1.28 & 5.47 & .02 & 1.19 & 3.73 & .03 & 1.27 & 5.45 & - \\
\hline \multirow{3}{*}{ FRB } & $1 / 3$ & 1.16 & 1.63 & 1.46 & 1.37 & 2.85 & 2.42 & .96 & 7.41 & - \\
\hline & 1 & 1.19 & 1.21 & 1.97 & 1.42 & 2.14 & 3.46 & .94 & 8.70 & - \\
\hline & 3 & 1.19 & .74 & 2.16 & 1.41 & 1.32 & 3.74 & .93 & 8.47 & - \\
\hline \multirow{5}{*}{ MSR } & 0 & .96 & 4.14 & .02 & .92 & 2.21 & -.09 & .95 & 3.90 & - \\
\hline & $1 / 3$ & 1.25 & 2.91 & 1.92 & 1.30 & 3.14 & 2.21 & -.06 & 3.11 & - \\
\hline & 1 & 1.22 & 1.71 & 2.01 & 1.26 & 1.76 & 2.20 & -.38 & 1.79 & - \\
\hline & 3 & 1.19 & .99 & 2.03 & 1.22 & 1.00 & 2.14 & -.52 & 1.14 & - \\
\hline & 0 & 1.04 & 3.59 & .11 & 1.16 & 4.39 & .21 & 1.14 & 4.92 & - \\
\hline \multirow{3}{*}{ TMCM } & $1 / 3$ & .97 & 1.33 & 1.28 & .98 & 1.32 & 1.27 & .73 & 3.41 & - \\
\hline & 1 & 1.31 & 1.52 & 4.93 & .96 & 0.55 & 1.43 & .58 & 3.02 & - \\
\hline & 3 & 1.33 & .85 & 5.10 & 1.33 & 0.77 & 5.00 & .50 & 7.91 & - \\
\hline
\end{tabular}

Notes: For each model, each value of the preference parameter $\lambda$, and each specification of the policy rule, this table indicates the optimal coefficients $\rho, \alpha$ and $\beta$. FB4 rules utilize the fourquarter average inflation rate $\tilde{\pi}$, while FB1 rules utilize the one-quarter annualized inflation rate $\pi$; FB4XG rules have no explicit response to the output gap (that is, $\beta \equiv 0$ ). 
Table A3: Coefficients of Optimized FB4 Rules with Fixed Forecast Horizons

\begin{tabular}{|c|c|c|c|c|c|c|c|c|c|c|}
\hline \multirow[t]{2}{*}{ Model } & \multirow[t]{2}{*}{$\lambda$} & \multicolumn{3}{|c|}{$\theta=4, \kappa=0$} & \multicolumn{3}{|c|}{$\theta=8, \kappa=0$} & \multicolumn{3}{|c|}{$\theta=4, \kappa=4$} \\
\hline & & $\rho$ & $\alpha$ & $\beta$ & $\rho$ & $\alpha$ & $\beta$ & $\rho$ & $\alpha$ & $\beta$ \\
\hline \multirow{5}{*}{ FM } & 0 & .88 & .65 & -.00 & 1.19 & 2.05 & -.04 & 1.03 & .78 & .11 \\
\hline & $1 / 3$ & .94 & .54 & .32 & 1.07 & .58 & .46 & 1.00 & .85 & .49 \\
\hline & 1 & .85 & .39 & .50 & .84 & .61 & .50 & 1.02 & .73 & .90 \\
\hline & 3 & .82 & .21 & .64 & .82 & .32 & .60 & 1.04 & .48 & 1.13 \\
\hline & 0 & 1.27 & 5.31 & .04 & 2.50 & 49.22 & -.05 & 1.28 & 5.53 & .02 \\
\hline \multirow{3}{*}{ FRB } & $1 / 3$ & 1.01 & 1.01 & 1.00 & 0.99 & 1.13 & .96 & 2.12 & 8.65 & 6.79 \\
\hline & 1 & 1.03 & .54 & 1.10 & 1.03 & .61 & 1.08 & 2.22 & 5.97 & 8.84 \\
\hline & 3 & 1.03 & .30 & 1.13 & 1.03 & .33 & 1.12 & 2.11 & 3.38 & 8.69 \\
\hline \multirow{5}{*}{ MSR } & 0 & .95 & 8.39 & -.33 & .97 & 18.96 & .65 & 1.00 & 4.16 & -.35 \\
\hline & $1 / 3$ & 1.11 & 2.21 & 1.38 & 1.12 & 3.85 & 1.44 & 1.80 & 28.00 & 24.00 \\
\hline & 1 & 1.08 & 1.20 & 1.42 & 1.09 & 1.81 & 1.47 & 1.80 & 16.00 & 24.00 \\
\hline & 3 & 1.05 & .65 & 1.41 & 1.06 & .89 & 1.44 & 1.80 & 8.00 & 24.00 \\
\hline & 0 & 1.74 & 14.77 & .30 & 1.27 & 12.90 & 2.17 & 1.82 & 17.11 & .26 \\
\hline \multirow{3}{*}{ TMCM } & $1 / 3$ & 1.02 & 1.92 & 1.39 & 1.04 & 6.22 & 1.73 & 1.06 & 13.53 & 10.21 \\
\hline & 1 & .97 & .80 & 1.47 & .96 & .04 & 1.53 & 1.00 & 7.87 & 9.74 \\
\hline & 3 & .95 & .42 & 1.49 & .95 & .04 & 1.53 & 1.23 & 6.12 & 12.00 \\
\hline
\end{tabular}

\section{A.5 Additional Robustness Results}

Table A4 provides robustness results for each optimized fixed-horizon FB4 rule in each of the four macroeconometric models when the rule is implemented using model-consistent forecasts (following the approach described in Section 5.1), while Table A5 reports the performance of these rules using model-inconsistent forecasts (as in Section 5.2). Table A6 reports on the performance of the policy rules taken from the literature (described in Section 2), when each rule is implemented using modelconsistent forecasts. 


\begin{tabular}{|c|c|c|c|c|c|c|c|c|c|c|c|}
\hline \multirow{2}{*}{\multicolumn{2}{|c|}{$\begin{array}{l}\text { Forecast } \\
\text { Horizons }\end{array}$}} & \multicolumn{5}{|c|}{$\lambda=0$} & \multicolumn{5}{|c|}{$\lambda=1 / 3$} \\
\hline & & \multirow{2}{*}{$\begin{array}{c}\text { Rule- } \\
\text { Gen. } \\
\text { Model }\end{array}$} & \multicolumn{4}{|c|}{ True Economy Model } & \multirow{2}{*}{$\begin{array}{c}\text { Rule- } \\
\text { Gen. } \\
\text { Model } \\
\end{array}$} & \multicolumn{4}{|c|}{ True Economy Model } \\
\hline$\theta$ & $\kappa$ & & FM & FRB & MSR & TMCM & & FM & FRB & MSR & TMCM \\
\hline \multirow[t]{4}{*}{4} & 0 & FM & 8 & 8 & 60 & 14 & FM & 2 & 15 & 13 & 2 \\
\hline & & FRB & 56 & -10 & 3 & -2 & FRB & 13 & 8 & 15 & 1 \\
\hline & & MSR & 5 & -4 & 5 & 2 & MSR & 19 & 17 & 9 & -1 \\
\hline & & TMCM & 145 & -9 & 25 & -2 & TMCM & 9 & 11 & 10 & 1 \\
\hline \multirow[t]{4}{*}{8} & 0 & FM & 3 & 4 & 9 & 23 & $\mathrm{FM}$ & 18 & 10 & 21 & 8 \\
\hline & & FRB & 1 & -4 & 20 & 15 & FRB & 16 & 14 & 23 & 5 \\
\hline & & MSR & 22 & 6 & 113 & ME & MSR & 14 & 49 & 10 & 5 \\
\hline & & TMCM & 36 & 37 & 269 & 24 & TMCM & 13 & 69 & 13 & 5 \\
\hline \multirow[t]{4}{*}{4} & 4 & $\mathrm{FM}$ & 1 & -1 & 17 & -7 & $\mathrm{FM}$ & 0 & 11 & 24 & 6 \\
\hline & & FRB & 68 & -10 & 8 & -5 & FRB & 8 & -5 & 10 & 3 \\
\hline & & MSR & 33 & 7 & 12 & 0 & MSR & 3 & -4 & 13 & $\mathrm{ME}$ \\
\hline & & TMCM & 145 & -8 & 3 & -2 & TMCM & 1 & -2 & 17 & 11 \\
\hline \multirow{2}{*}{\multicolumn{2}{|c|}{$\begin{array}{l}\text { Forecast } \\
\text { Horizons }\end{array}$}} & \multicolumn{5}{|c|}{$\lambda=1$} & \multicolumn{5}{|c|}{$\lambda=3$} \\
\hline & & \multirow{2}{*}{$\begin{array}{c}\text { Rule- } \\
\text { Gen. } \\
\text { Model }\end{array}$} & \multicolumn{4}{|c|}{ True Economy Model } & $\begin{array}{l}\text { Rule- } \\
\text { Gen. }\end{array}$ & \multicolumn{4}{|c|}{ True Economy Model } \\
\hline$\theta$ & $\kappa$ & & FM & FRB & MSR & TMCM & Model & FM & FRB & MSR & TMCM \\
\hline \multirow[t]{4}{*}{4} & 0 & $\mathrm{FM}$ & 4 & 27 & 22 & 7 & FM & 5 & 35 & 27 & 15 \\
\hline & & FRB & 19 & 7 & 12 & 1 & FRB & 25 & 4 & 8 & 1 \\
\hline & & MSR & 19 & 14 & 6 & 1 & MSR & 21 & 10 & 4 & 1 \\
\hline & & TMCM & 11 & 8 & 12 & 0 & TMCM & 12 & 6 & 9 & 0 \\
\hline \multirow[t]{4}{*}{8} & 0 & $\mathrm{FM}$ & 4 & 35 & 23 & 12 & $\mathrm{FM}$ & 3 & 23 & 15 & 5 \\
\hline & & FRB & 21 & 10 & 17 & 3 & FRB & 27 & 6 & 11 & 3 \\
\hline & & MSR & 18 & 28 & 7 & 4 & MSR & 21 & 16 & 4 & 4 \\
\hline & & TMCM & 272 & 77 & 222 & 2 & TMCM & 155 & 44 & 108 & 0 \\
\hline \multirow[t]{4}{*}{4} & 4 & $\mathrm{FM}$ & 0 & 12 & 39 & 8 & $\mathrm{FM}$ & 0 & 15 & 56 & 10 \\
\hline & & FRB & 9 & -6 & 18 & 4 & FRB & 12 & -8 & 27 & 4 \\
\hline & & MSR & 2 & -5 & 23 & $\mathrm{ME}$ & MSR & 2 & -7 & 35 & $\mathrm{ME}$ \\
\hline & & TMCM & 2 & 0 & $\mathrm{ME}$ & 25 & TMCM & 4 & -2 & 41 & 42 \\
\hline
\end{tabular}

Note: For a given value of $\lambda$ and a given combination of the inflation and output forecast horizons, the optimized rule is taken from the specified "rule-generating model" and is evaluated in each alternative "true economy model" using model-consistent forecasts. Each entry indicates the relative loss $(\% \Delta \mathcal{L})$ of the rule compared with the OB policy frontier of the true economy model; the notation "ME" indicates that the rule yields multiple equilibria in the specified model. 
Table A5: Robustness of Fixed-Horizon Rules with Model-Inconsistent Forecasts

Forecast

\begin{tabular}{|c|c|c|c|c|c|c|c|}
\hline \multicolumn{2}{|c|}{ Horizon } & \multirow[b]{2}{*}{$\lambda$} & \multicolumn{3}{|c|}{ Optimized for FM } & \multicolumn{2}{|c|}{ Optimized for MSR } \\
\hline$\theta$ & $\kappa$ & & FRB & MSR & TMCM & FRB & TMCM \\
\hline \multirow[t]{4}{*}{4} & 0 & 0 & 9 & 85 & 17 & 10 & 16 \\
\hline & & $1 / 3$ & 15 & 14 & 7 & 11 & 7 \\
\hline & & 1 & 25 & 23 & 13 & 8 & 8 \\
\hline & & 3 & 31 & 27 & 14 & 5 & 6 \\
\hline \multirow[t]{4}{*}{8} & 0 & 0 & 8 & 41 & 7 & 11 & 8 \\
\hline & & $1 / 3$ & 14 & 11 & 3 & 10 & 7 \\
\hline & & 1 & 27 & 26 & 15 & 8 & 8 \\
\hline & & 3 & 20 & 16 & 8 & 5 & 6 \\
\hline \multirow[t]{4}{*}{4} & 4 & 0 & 10 & 63 & 6 & 12 & 2 \\
\hline & & $1 / 3$ & 16 & 30 & 10 & 441 & 178 \\
\hline & & 1 & 21 & 20 & 16 & $\mathrm{ME}$ & 240 \\
\hline & & 3 & 29 & 27 & 21 & ME & 281 \\
\hline
\end{tabular}

Note: For each value of the preference parameter $\lambda$ and each choice of the inflation forecast horizon $\theta$ and output gap forecast horizon $\kappa$, the coefficients of the rule are optimized using the specified "rule-generating" model (either FM or MSR), and then this rule is evaluated in each alternative "true economy" model using forecasts obtained from the rule-generating model. Each entry indicates the percent deviation of the loss function from the outcome-based policy frontier of the true economy model $(\% \Delta \mathcal{L})$; the notation "ME" indicates that the rule yields multiple equilibria. 
Table A6: Performance of Rules from the Literature

\begin{tabular}{|c|c|c|c|c|c|c|c|c|c|c|}
\hline \multirow[b]{2}{*}{ Rule } & \multicolumn{5}{|c|}{$\lambda=0$} & \multicolumn{5}{|c|}{$\lambda=1 / 3$} \\
\hline & $\begin{array}{r}\text { Opt. } \\
\text { AD-AS }\end{array}$ & FM & FRB & MSR & TMCM & $\begin{array}{r}\text { Opt. } \\
\text { AD-AS }\end{array}$ & FM & FRB & MSR & TMCM \\
\hline A & 551 & 46 & 47 & 419 & 50 & 144 & 7 & 47 & 62 & 48 \\
\hline B & 160 & 32 & 32 & 204 & 38 & 71 & 6 & 92 & 40 & 33 \\
\hline $\mathrm{C}$ & $\mathrm{ME}$ & 144 & 141 & 656 & 137 & $\mathrm{ME}$ & 49 & 156 & 135 & 109 \\
\hline $\mathrm{D}$ & $\mathrm{ME}$ & 107 & 44 & 367 & 63 & $\mathrm{ME}$ & 10 & 60 & 105 & 55 \\
\hline $\mathrm{E}$ & 176 & 5 & -7 & 30 & 2 & 91 & 71 & 193 & 121 & 15 \\
\hline $\mathrm{F}$ & $\mathrm{ME}$ & 100 & $\mathrm{ME}$ & 514 & 138 & ME & 19 & ME & 117 & 117 \\
\hline G & $\mathrm{ME}$ & 60 & $\mathrm{ME}$ & $\mathrm{ME}$ & $\mathrm{ME}$ & $\mathrm{ME}$ & 8 & $\mathrm{ME}$ & $\mathrm{ME}$ & $\mathrm{ME}$ \\
\hline $\mathrm{H}$ & $\mathrm{ME}$ & 56 & $\mathrm{ME}$ & $\mathrm{ME}$ & $\mathrm{ME}$ & ME & 6 & $\mathrm{ME}$ & $\mathrm{ME}$ & $\mathrm{ME}$ \\
\hline I & $\mathrm{ME}$ & $\mathrm{ME}$ & $\mathrm{ME}$ & $\mathrm{ME}$ & $\mathrm{ME}$ & ME & $\mathrm{ME}$ & ME & $\mathrm{ME}$ & $\mathrm{ME}$ \\
\hline $\mathrm{J}$ & $\mathrm{ME}$ & 121 & $\mathrm{ME}$ & $\mathrm{ME}$ & $\mathrm{ME}$ & ME & 18 & ME & $\mathrm{ME}$ & $\mathrm{ME}$ \\
\hline \multirow[t]{2}{*}{ K } & $\mathrm{ME}$ & 125 & $\mathrm{ME}$ & 612 & 262 & $\mathrm{ME}$ & 38 & $\mathrm{ME}$ & 130 & 210 \\
\hline & \multicolumn{5}{|c|}{$\lambda=1$} & \multicolumn{5}{|c|}{$\lambda=3$} \\
\hline Rule & $\begin{array}{r}\text { Opt. } \\
\text { AD-AS }\end{array}$ & FM & FRB & MSR & TMCM & $\begin{array}{r}\text { Opt. } \\
\text { AD-AS }\end{array}$ & FM & FRB & MSR & TMCM \\
\hline A & 332 & 17 & 110 & 108 & 71 & 628 & 53 & 211 & 187 & 99 \\
\hline B & 90 & 14 & 211 & 53 & 36 & 101 & 42 & 396 & 81 & 41 \\
\hline $\mathrm{C}$ & $\mathrm{ME}$ & 29 & 273 & 136 & 102 & ME & 34 & 424 & 166 & 100 \\
\hline $\mathrm{D}$ & $\mathrm{ME}$ & 19 & 135 & 185 & 76 & $\mathrm{ME}$ & 61 & 77 & 301 & 103 \\
\hline $\mathrm{E}$ & 275 & 179 & 462 & 246 & 34 & 303 & 373 & 882 & 387 & 51 \\
\hline $\mathrm{F}$ & $\mathrm{ME}$ & 33 & $\mathrm{ME}$ & 179 & 131 & $\mathrm{ME}$ & 80 & $\mathrm{ME}$ & 277 & 150 \\
\hline $\mathrm{G}$ & $\mathrm{ME}$ & 18 & $\mathrm{ME}$ & $\mathrm{ME}$ & $\mathrm{ME}$ & $\mathrm{ME}$ & 56 & $\mathrm{ME}$ & $\mathrm{ME}$ & $\mathrm{ME}$ \\
\hline $\mathrm{H}$ & $\mathrm{ME}$ & 15 & $\mathrm{ME}$ & $\mathrm{ME}$ & $\mathrm{ME}$ & ME & 50 & ME & $\mathrm{ME}$ & $\mathrm{ME}$ \\
\hline I & $\mathrm{ME}$ & $\mathrm{ME}$ & $\mathrm{ME}$ & $\mathrm{ME}$ & $\mathrm{ME}$ & $\mathrm{ME}$ & $\mathrm{ME}$ & $\mathrm{ME}$ & $\mathrm{ME}$ & $\mathrm{ME}$ \\
\hline $\mathrm{J}$ & $\mathrm{ME}$ & 22 & $\mathrm{ME}$ & $\mathrm{ME}$ & $\mathrm{ME}$ & $\mathrm{ME}$ & 56 & $\mathrm{ME}$ & $\mathrm{ME}$ & $\mathrm{ME}$ \\
\hline $\mathrm{K}$ & $\mathrm{ME}$ & 36 & $\mathrm{ME}$ & 158 & 201 & $\mathrm{ME}$ & 64 & $\mathrm{ME}$ & 214 & 198 \\
\hline
\end{tabular}

Notes: The specification of each rule is given in Table 1. The rule is evaluated in each alternative "true economy" model using model-consistent forecasts. Each entry indicates the relative loss $(\% \Delta \mathcal{L})$ of the rule compared with the OB policy frontier of the true economy model; the notation "ME" indicates that the rule yields multiple equilibria in the specified model. 


\section{References}

Amano, Robert, Don Coletti, and Tiff Macklem, "Monetary Rules when Economic Behaviour Changes," April 1999. Bank of Canada Working Paper 99-8.

Anderson, Gary and George Moore, "A Linear Algebraic Procedure for Solving Linear Perfect Foresight Models," Economics Letters, 1985, 17, 247-252.

Balvers, Ronald and Thomas Cosimano, "Inflation Variability and Gradualist Monetary Policy," Review of Economic Studies, 1994, 61, 721-738.

Batini, Nicoletta and Andrew Haldane, "Forward-Looking Rules for Monetary Policy," in John B. Taylor, ed., Monetary Policy Rules, Chicago: University of Chicago Press, 1999, pp. 157-192.

_ _ and Edward Nelson, "Optimal Horizons for Inflation Targeting," Journal of Economic Dynamics and Control, June 2001, 25 (6-7), 891-910.

Becker, R. G., B. Dwolatsky, E. Karakitsos, and B. Rustem, "The Simulataneous Use of Rival Models in Policy Optimisation," Economic Journal, 1986, 96, 425-48.

Benhabib, Jess, Stephanie Schmitt-Grohé, and Martín Uribe, "Monetary Policy and Multiple Equilibria," American Economic Review, 2001, 91 (1), 167-186.

Bernanke, Ben S. and Frederic S. Mishkin, "Inflation Targeting: A New Framework for Monetary Policy?," Journal of Economic Perspectives, 1997, 11 (2), 97-116.

and Michael Woodford, "Inflation Forecasts and Monetary Policy," Journal of Money, Credit and Banking, 1997, 24, 65-84.

, Thomas Laubach, Frederic Mishkin, and Adam Posen, Inflation Targeting: Lessons from the International Experience, Princeton, NJ: Princeton University Press, 1999.

Black, Richard, Tiff Macklem, and David Rose, "On Policy Rules for Price Stability," in "Price Stability, Inflation Targets and Monetary Policy, Proceedings of a Conference Held by the Bank of Canada" Bank of Canada Ottawa, Canada May 1997.

, Vincenzo Cassino, Aaron Drew, Eric Hansen, Benjamin Hunt, David Rose, and Alasdair Scott, "The Forecasting and Policy System: The Core Model," 1997. Reserve Bank of New Zealand Research Paper No. 43.

Blanchard, Olivier Jean and Charles M. Kahn, "The Solution of Linear Difference Models under Rational Expectations," Econometrica, July 1980, 48, 1305-13.

Brainard, William, "Uncertainty and the Effectiveness of Policy," American Economic Review, $1967,57,411-425$.

Brayton, Flint, Andrew Levin, Ralph Tryon, and John Williams, "The Evolution of Macro Models at the Federal Reserve Board," Carnegie Rochester Conference Series on Public Policy, 1997, 47, 43-81.

, Eileen Mauskopf, David Reifschneider, Peter Tinsley, and John Williams, "The Role of Expectations in the FRB/US Macroeconomic Model," Federal Reserve Bulletin, 1997, $83(4), 227-245$.

Bryant, Ralph C., Peter Hooper, and Catherine L. Mann, eds, Evaluating Policy Regimes: New Research in Empirical Macroeconomics, Washington, DC: Brookings Institution, 1993. 
Buiter, Willem H. and Ian Jewitt, "Staggered Wage Setting with Real Wage Relativities: Variations on a Theme by Taylor," The Manchester School, 1981, 49, 211-228.

Carlstrom, Charles T. and Timothy S. Fuerst, "Forward-Looking Versus Backward-Looking Taylor Rules," August 2000. Federal Reserve Bank of Cleaveland Working Paper 00-09.

Chinn, Menzie and Michael Dooley, "Monetary Policy in Japan, Germany and the United States: Does One Size Fit All?," July 1997. NBER Working Paper No. 6092.

Christiano, Lawrence J. and Christopher Gust, "Comment on "Robustness of Simple Policy Rules under Model Uncertainty"," in John B. Taylor, ed., Monetary Policy Rules, Chicago: University of Chicago Press, 1999, chapter 6, pp. 299-316.

, Martin Eichenbaum, and Charles L. Evans, "The Effects of Monetary Policy Shocks: Some Evidence from the Flow of Funds," Review of Economics and Statistics, 1996, 78, 16-34.

Christodoulakis, Nico, David Kemball-Cook, and Paul Levine, "The Design of Economic Policy under Model Uncertainty," Computational Economics, 1993, 6, 219-40.

Clarida, Richard and Mark Gertler, "How the Bundesbank Conducts Monetary Policy," in Christina Romer and David Romer, eds., Reducing Inflation: Motivation and Strategy, Chicago: University of Chicago Press, 1997.

, Jordi Gali, and Mark Gertler, "Monetary Policy Rules in Practice: Some International Evidence," European Economic Review, 1998, 42, 1003-1067.

and ___ , "Monetary Policy Rules and Macroeconomic Stability: Evidence and Some Theory," Quarterly Journal of Economics, 1999, 115, 147-180.

_ _ , and _ _ "The Science of Monetary Policy: A New Keynesian Perspective," jel, 1999, 37, 1661-1707.

de Brouwer, Gordon and Luci Ellis, "Forward-looking Behaviour and Credibility: Some Evidence and Implications for Policy," 1998. Research Discussion Paper 9803, Reserve Bank of Australia.

Erceg, Christopher J. and Andrew Levin, "Imperfect Credibility and Inflation Persistence," July 2000. manuscript, Federal Reserve Board.

, Dale W. Henderson, and Andrew T. Levin, "Optimal Monetary Policy with Staggered Wage and Price Contracts," Journal of Monetary Economics, 2000, 46, 281-313.

Estrella, Arturo and Jeffrey C. Fuhrer, "Dynamic Inconsistencies: Counterfactual Implications of a Class of Rational Expectations Models," 1998. Federal Reserve Bank of Boston Working Paper 98-5.

Frankel, Jeffery A. and Katherine Rockett, "International Macroeconomic Policy Coordination when Policymakers Do Not Agree on the True Model," American Economic Review, 1988, $78,318-40$.

Fuhrer, Jeffrey C., "Inflation/Output Variance Trade-Offs and Optimal Monetary Policy," Journal of Money, Credit and Banking, 1997, 29, 214-34.

, "Towards a Compact, Empirically-Verified Rational Expectations Model for Monetary Policy Analysis," Carnegie Rochester Conference Series on Public Policy, 1997, 47, 197-230.

and Brian Madigan, "Monetary Policy when Interest Rates are Bounded at Zero," Review of Economics and Statistics, November 1997, 79, 573-85.

and George Moore, "Inflation Persistence," Quarterly Journal of Economics, February 1995, 110, 127-59. 
Giannoni, Marc P., "Optimal Interest-Rate Rules in a Forward-Looking Model, and Inflation Stabilization versus Price-Level Stabilization," September 2000. Federal Reserve Bank of New York, manuscript.

Goodfriend, Marvin, "Interest Rate Rules and the Conduct of Monetary Policy," Carnegie Rochester Conference Series on Public Policy, 1991, 34, 7-30.

Goodhart, Charles, "The Inflation Forecast," 2000. manuscript.

Haldane, Andrew, ed., Targeting Inflation, London: Bank of England, 1995.

Hansen, Lars P. and Thomas J. Sargent, "Discounted Robust Filtering and Control in the Frequency Domain," 1997. manuscript, University of Chicago.

Holtham, Gerald and Andrew Hughes-Hallett, "International Macroeconomic Policy Coordination when Policymakers Do Not Agree on the True Model: Comment," American Economic Review, 1992, 82, 1043-56.

Isard, Peter, Douglas Laxton, and Ann-Charlotte Eliasson, "Simple Monetary Policy Rules under Model Uncertainty," 1999. IMF Working Paper 99/75.

Karakitsos, E. and B. Rustem, "Optimally Derived Fixed Rules and Indicators," Journal of Economic Dynamics and Control, 1984, 8, 33-64.

Kendrick, David, "Caution and Probing in a Macroeconomic Model," Journal of Economic Dynamics and Control, 1982, 4, 149-170.

Kerr, W. and Robert G. King, "Limits on Interest Rate Rules in an IS Model," Federal Reserve Bank of Richmond Economic Quarterly, 1996, 82, 47-75.

King, Mervyn, "Changes in UK Monetary Policy: Rules and Discretion in Practice," Journal of Monetary Economics, June 1997, 39 (1), 81-97.

Leiderman, Leonardo and Lars E. O. Svensson, eds, Inflation Targets, London: Centre for Economic Policy Research, 1995.

Levin, Andrew, Volker Wieland, and John C. Williams, "Robustness of Simple Monetary Policy Rules under Model Uncertainty," in John B. Taylor, ed., Monetary Policy Rules, Chicago: University of Chicago Press, 1999, pp. 263-299.

McCallum, Bennett, "Robustness Properties of a Rule for Monetary Policy," Carnegie Rochester Conference Series on Public Policy, 1988, 29, 173-204.

, "Roles of the Minimal State Variable Criterion in Rational Expectations Models," 1999. manuscript.

, "Theoretical Analysis Regarding a Zero Lower Bound on Nominal Interest Rates," Journal of Money, Credit and Banking, 2000, 32.

Orphanides, Athanasios, "Monetary Policy Evaluation with Noisy Information," 1998. FEDS Working Paper 1998-50, Board of Governors of the Federal Reserve System.

, "Monetary Policy Rules Based on Real-Time Data," 1998. FEDS Working Paper 1998-3, Board of Governors of the Federal Reserve System.

and David W. Wilcox, "The Opportunistic Approach to Disinflation," 1996. FEDS Working Paper 1996-24, Board of Governors of the Federal Reserve System.

and Volker Wieland, "Price Stability and Monetary Policy Effectiveness when Nominal Interest Rates are Bounded at Zero," 1998. FEDS Working Paper 1998-35, Board of Governors of the Federal Reserve System. 
and __ "Efficient Monetary Policy Near Price Stability," 1999. FEDS Working Paper 1999-67, Board of Governors of the Federal Reserve System.

, David Small, Volker Wieland, and David W. Wilcox, "A Quantitative Exploration of the Opportunistic Approach to Disinflation," 1997. FEDS Working Paper 1997-36, Board of Governors of the Federal Reserve System.

, Frederico Finan, Richard Porter, David Reifschneider, and Robert Tetlow, "Errors in the Measurement of the Output Gap and the Design of Monetary Policy," Journal of Economics and Business, 2000, 52.

Reifschneider, David and John C. Williams, "Three Lessons for Monetary Policy in a Low Inflation Era," Journal of Money, Credit and Banking, November 2000, 32 (4), 936-966.

, Robert Tetlow, and John Williams, "Aggregate Disturbances, Monetary Policy, and the Macroeconomy: The FRB/US Perspective," Federal Reserve Bulletin, 1999, 85 (1), 1-19.

Rotemberg, Julio J., "Sticky Prices in the United States," Journal of Political Economy, 1982, $90(4), 1187-1211$.

_ _ and Michael Woodford, "An Optimization-Based Econometric Framework for the Evaluation of Monetary Policy," in "NBER Macroeconomics Annual 1997," Cambridge, MA: The MIT Press, 1997, pp. 297-346.

_ and __ , "Interest-Rate Rules in an Estimated Sticky Price Model," in John B. Taylor, ed., Monetary Policy Rules, Chicago: University of Chicago Press, 1999, pp. 57-119.

Rudebusch, Glenn D. and Lars E. O. Svensson, "Policy Rules for Inflation Targeting," in John B. Taylor, ed., Monetary Policy Rules, Chicago: University of Chicago Press, 1999, pp. $203-253$.

Sack, Brian and Volker Wieland, "Interest Rate Smoothing and Optimal Monetary Policy," Journal of Economics and Business, 2000, 52.

Sargent, Thomas and Neil Wallace, "Rational Expectations, the Optimal Monetary Instrument, and the Optimal Money Supply Rule," Journal of Political Economy, 1975.

Schaecter, Andrea, Mark R. Stone, and Mark Zelmer, "Adopting Inflation Targeting: Practical Issues for Emerging Market Countries," December 2000. IMF Occasional Paper No. 202.

Smets, Frank, "Output Gap Uncertainty: Does it matter for the Taylor Rule?," in B. Hunt and A. Orr, eds., Monetary Policy under Uncertainty, Wellington, New Zealand: Reserve Bank of New Zealand, 1999.

Söderlind, Paul, "Solution and Estimation of RE Macromodels with Optimal Policy," European Economic Review, 1999, 43, 813-823.

Stock, James H. and Alexi Onatski, "Robust Monetary Policy under Model Uncertainty in a Small Model of the U.S. Economy," 1999. NBER Working Paper No. 7490.

Svensson, Lars E. O., "Inflation Forecast Targeting: Implementing and Monitoring Inflation Targets," European Economic Review, 1997.

, "Inflation Targeting as a Monetary Policy Rule," Journal of Monetary Economics, June 1999, $43(3), 607-654$.

, "Requiem for Forecast-Based Instrument Rules," March 2001. manuscript, Institute for International Economic Studies, Stockholm University. 
and Michael Woodford, "Implementing Optimal Policy through Inflation-Forecast Targeting," November 1999. manuscript, Princeton University.

and __ , "Indicator Variables for Optimal Policy," September 2000. NBER Working Paper 7953.

Swanson, Eric T., "On Signal Extraction and Non-Certainty-Equivalence in Optimal Monetary Policy Rules," 2000. FEDS Working Paper 2000-32, Board of Governors of the Federal Reserve System.

Taylor, John B., "Aggregate Dynamics and Staggered Contracts," Journal of Political Economy, $1980,88,1-23$.

_ , "Introduction," in John B. Taylor, ed., Monetary Policy Rules, Chicago: University of Chicago Press, 1999, pp. 1-14.

"The Robustness and Efficiency of Monetary Policy Rules as Guidelines for Interest Rate Setting by the European Central Bank," Journal of Monetary Economics, 1999, 43 (3), 655679 .

, ed., Monetary Policy Rules, Chicago: University of Chicago Press, 1999.

Tetlow, Robert, "Inflation Targeting and Target Instability," January 2000. Federal Reserve Board, FEDS WP 2000-1.

and Peter von zur Muehlen, "Robust Monetary Policy with Misspecified Models: Does Model Uncertainty Always Call for Attenuated Policy?," May 2000. Federal Reserve Board, FEDS WP 2000-28.

Tinsley, Peter A., "Fitting Both Data and Theories: Polynomial Adjustment Costs and ErrorCorrection Rules," June 1993. FEDS Working Paper 1993-21.

von zur Muehlen, Peter, "Activist vs. Non-Activist Monetary Policy: Optimal Rules under Extreme Uncertainty," 1982. manuscript, Federal Reserve Board.

Wieland, Volker, "Monetary Policy, Parameter Uncertainty and Optimal Learning," Journal of Monetary Economics, 2000, 46, 199-228.

Williams, John C., "Simple Rules for Monetary Policy," February 1999. FEDS Working Paper 1999-12.

Wolman, Alexander L., "Real Implications of the Zero Bound on Nominal Interest Rates," November 1998. Federal Reserve Bank of Richmond working paper.

Woodford, Michael, "Optimal Monetary Policy Inertia," Manchester School, 1999, pp. 1-35.

__ , "A Neo-Wicksellian Framework for the Analysis of Monetary Policy," September 2000. manuscript, Princeton University.

__ , "Pitfalls of Forward-Looking Monetary Policy," American Economic Association Papers and Proceedings, May 2000, 90 (2), 100-104.

__ "The Taylor Rule and Optimal Monetary Policy," American Economic Association Papers and Proceedings, May 2001, 91 (2).

Yun, T., "Nominal Price Rigidity, Money Supply Endogeneity, and Business Cycles," Journal of Monetary Economics, 1996, 37, 345-370. 


\section{European Central Bank Working Paper Series}

I "A global hazard index for the world foreign exchange markets" by V. Brousseau and F. Scacciavillani, May 1999.

2 "What does the single monetary policy do? A SVAR benchmark for the European Central Bank" by C. Monticelli and O. Tristani, May 1999.

3 "Fiscal policy effectiveness and neutrality results in a non-Ricardian world" by C. Detken, May 1999.

4 "From the ERM to the euro: new evidence on economic and policy convergence among EU countries” by I. Angeloni and L. Dedola, May 1999.

5 “Core inflation: a review of some conceptual issues" by M. Wynne, May 1999.

6 "The demand for M3 in the euro area" by G. Coenen and J.-L. Vega, September 1999.

7 “A cross-country comparison of market structures in European banking” by O. de Bandt and E. P. Davis, September 1999.

8 “Inflation zone targeting” by A. Orphanides and V. Wieland, October 1999.

9 "Asymptotic confidence bands for the estimated autocovariance and autocorrelation functions of vector autoregressive models" by G. Coenen, January 2000.

10 "On the effectiveness of sterilized foreign exchange intervention" by R. Fatum, February 2000.

II "Is the yield curve a useful information variable for the Eurosystem?" by J. M. Berk and P. van Bergeijk, February 2000.

12 “Indicator variables for optimal policy” by L. E. O. Svensson and M. Woodford, February 2000.

13 “Monetary policy with uncertain parameters” by U. Söderström, February 2000.

14 "Assessing nominal income rules for monetary policy with model and data uncertainty" by G. D. Rudebusch, February 2000.

15 "The quest for prosperity without inflation" by A. Orphanides, March 2000.

16 "Estimating the implied distribution of the future short term interest rate using the LongstaffSchwartz model” by P. Hördahl, March 2000.

17 "Alternative measures of the NAIRU in the euro area: estimates and assessment" by S. Fabiani and R. Mestre, March 2000.

18 "House prices and the macroeconomy in Europe: Results from a structural VAR analysis" by M. lacoviello, April 2000. 
19 "The euro and international capital markets" by C. Detken and P. Hartmann, April 2000.

20 "Convergence of fiscal policies in the euro area" by O. De Bandt and F. P. Mongelli, May 2000.

21 "Firm size and monetary policy transmission: evidence from German business survey data" by M. Ehrmann, May 2000.

22 "Regulating access to international large value payment systems" by C. Holthausen and T. Rønde, June 2000.

23 “Escaping Nash inflation” by In-Koo Cho and T. J. Sargent, June 2000.

24 "What horizon for price stability" by F. Smets, July 2000.

25 "Caution and conservatism in the making of monetary policy" by P. Schellekens, July 2000.

26 "Which kind of transparency? On the need for clarity in monetary policy-making" by B. Winkler, August 2000.

27 "This is what the US leading indicators lead" by M. Camacho and G. Perez-Quiros, August 2000.

28 "Learning, uncertainty and central bank activism in an economy with strategic interactions" by M. Ellison and N. Valla, August 2000.

29 "The sources of unemployment fluctuations: an empirical application to the Italian case" by S. Fabiani, A. Locarno, G. Oneto and P. Sestito, September 2000.

30 "A small estimated euro area model with rational expectations and nominal rigidities" by G. Coenen and V. Wieland, September 2000.

3I "The disappearing tax base: Is foreign direct investment eroding corporate income taxes?" by R. Gropp and K. Kostial, September 2000.

32 "Can indeterminacy explain the short-run non-neutrality of money?" by F. De Fiore, September 2000.

33 "The information content of M3 for future inflation" by C. Trecroci and J. L. Vega, October 2000.

34 "Capital market development, corporate governance and the credibility of exchange rate pegs” by O. Castrén and T. Takalo, October 2000.

35 "Systemic risk: A survey" by O. De Bandt and P. Hartmann, November 2000.

36 "Measuring core inflation in the euro area" by C. Morana, November 2000.

37 "Business fixed investment: Evidence of a financial accelerator in Europe" by P. Vermeulen, November 2000. 
38 "The optimal inflation tax when taxes are costly to collect" by F. De Fiore, November 2000.

39 "A money demand system for euro area M3" by C. Brand and N. Cassola, November 2000.

40 "Financial structure and the interest rate channel of ECB monetary policy" by B. Mojon, November 2000.

4I "Why adopt transparency? The publication of central bank forecasts" by P. M. Geraats, January 2001 .

42 "An area-wide model (AWM) for the euro area" by G. Fagan, J. Henry and R. Mestre, January 2001 .

43 "Sources of economic renewal: from the traditional firm to the knowledge firm" by D. R. Palenzuela, February 2001.

44 "The supply and demand for eurosystem deposits - The first 18 months" by U. Bindseil and F. Seitz, February 200I.

45 "Testing the Rank of the Hankel matrix: a statistical approach" by G. Camba-Mendez and G. Kapetanios, February 200I.

46 "A two-factor model of the German term structure of interest rates" by N. Cassola and J. B. Luís, February 200I.

47 "Deposit insurance and moral hazard: does the counterfactual matter?" by R. Gropp and J. Vesala, February 200I.

48 "Financial market integration in Europe: on the effects of EMU on stock markets" by M. Fratzscher, March 2001 .

49 "Business cycle and monetary policy analysis in a structural sticky-price model of the euro area” by M. Casares, March $200 \mathrm{I}$.

50 "Employment and productivity growth in service and manufacturing sectors in France, Germany and the US” by T. von Wachter, March 2001.

5I "The functional form of the demand for euro area MI" by L. Stracca, March 200 I.

52 "Are the effects of monetary policy in the euro area greater in recessions than in booms?" by G. Peersman and F. Smets, March 2001.

53 "An evaluation of some measures of core inflation for the euro area" by J.-L. Vega and M. A. Wynne, April 200I.

54 “Assessment criteria for output gap estimates" by G. Camba-Méndez and D. R. Palenzuela, April 2001.

55 "Modelling the demand for loans to the private sector in the euro area" by A. Calza,

G. Gartner and J. Sousa, April 200I. 
56 "Stabilization policy in a two country model and the role of financial frictions" by E. Faia, April 2001.

57 “Model-based indicators of labour market rigidity" by S. Fabiani and D. Rodriguez-Palenzuela, April 2001.

58 "Business cycle asymmetries in stock returns: evidence from higher order moments and conditional densities" by G. Perez-Quiros and A. Timmermann, April 200I.

59 “Uncertain potential output: implications for monetary policy” by M. Ehrmann and F. Smets, April 2001.

60 "A multi-country trend indicator for euro area inflation: computation and properties" by E. Angelini, J. Henry and R. Mestre, April 200I.

61 "Diffusion index-based inflation forecasts for the euro area" by E. Angelini, J. Henry and R. Mestre, April 200I.

62 "Spectral based methods to identify common trends and common cycles" by G. C. Mendez and G. Kapetanios, April $200 \mathrm{I}$.

63 "Does money lead inflation in the euro area?" by S. N. Altimari, May $200 \mathrm{I}$.

64 "Exchange rate volatility and euro area imports" by R. Anderton and F. Skudelny, May $200 \mathrm{I}$.

65 "A system approach for measuring the euro area NAIRU” by S. Fabiani and R. Mestre, May 200I.

66 "Can short-term foreign exchange volatility be predicted by the Global Hazard Index?" by V. Brousseau and F. Scacciavillani, June 200I.

67 "The daily market for funds in Europe: Has something changed with the EMU?" by G. P. Quiros and H. R. Mendizabal, June 200I.

68 "The performance of forecast-based monetary policy rules under model uncertainty" by A. Levin, V. Wieland and J. C.Williams, July 2001. 